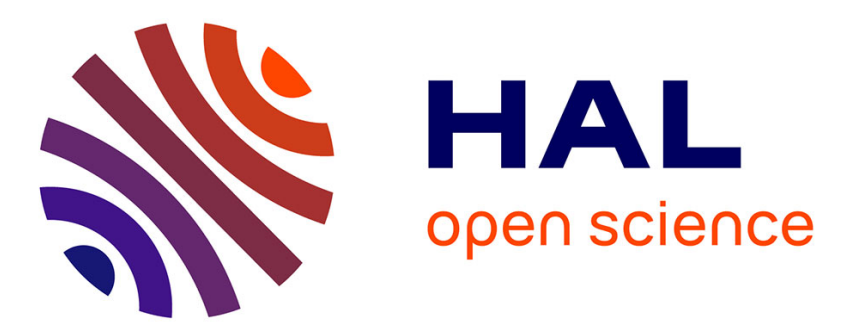

\title{
Serine protease inhibitors to treat inflammation: a patent review (2011-2016)
}

Feryel Soualmia, Chahrazade El Amri

\section{To cite this version:}

Feryel Soualmia, Chahrazade El Amri. Serine protease inhibitors to treat inflammation: a patent review (2011-2016). Expert Opinion on Therapeutic Patents, inPress, 28 (2), pp.93-110. 10.1080/13543776.2018.1406478 . hal-01656928

\section{HAL Id: hal-01656928 \\ https://hal.sorbonne-universite.fr/hal-01656928}

Submitted on 6 Dec 2017

HAL is a multi-disciplinary open access archive for the deposit and dissemination of scientific research documents, whether they are published or not. The documents may come from teaching and research institutions in France or abroad, or from public or private research centers.
L'archive ouverte pluridisciplinaire HAL, est destinée au dépôt et à la diffusion de documents scientifiques de niveau recherche, publiés ou non, émanant des établissements d'enseignement et de recherche français ou étrangers, des laboratoires publics ou privés. 


\title{
Serine protease inhibitors to treat inflammation: a patent review (2011-2016)
}

\author{
Feryel Soualmia and Chahrazade El Amri \\ B2A, Biological Adaptation and Ageing, Integrated Cellular Ageing and Inflammation, Molecular \& Functional Enzymology, Sorbonne Universités, \\ UPMC Univ Paris 06, UMR 8256, Paris, France
}

\begin{abstract}
Introduction: Inflammation is a physiological part of the complex biological response of tissues to counteract various harmful signals. This process involves diverse actors such as immune cells, blood vessels, and nerves as sources of mediators for inflammation control. Among them serine proteases are key elements in both physiological and pathological inflammation.

Areas covered: Serine protease inhibitors to treat inflammatory diseases are being actively investigated by various industrial and academic institutions. The present review covers patent literature on serine protease inhibitors for the therapy of inflammatory diseases patented between 2011 and 2016.

Expert opinion: Serine proteases regulating inflammation are versatile enzymes, usually involved in proinflammatory cytokine production and activation of immune cells. Their dysregulation during inflammation can have devastating consequences, promoting various diseases including skin and lung inflammation, neuroinflammation, and inflammatory arthritis. Several serine proteases were selected for their contribution to inflammatory diseases and significant efforts that are spread to develop inhibitors. Strategies developed for inhibitor identification consist on either peptide-based inhibitor derived from endogenous protein inhibitors or small-organic molecules. It is also worth noting that among the recent patents on serine protease inhibitors related to inflammation a significant number are related to retinal vascular dysfunction and skin diseases.
\end{abstract}

KEYWORDS

Serine proteases;

inflammation; therapeutical

inhibitors; kallikreins;

plasmin; neutrophil elastase;

skin inflammation; lung

inflammation;

gastrointestinal

inflammation

\section{Introduction}

Proteolytic enzymes or proteases catalyze the hydrolysis of the established peptide bonds between the amino acids of the proteins and peptides. Much more than degradation enzymes, they are considered nowadays as important signaling molecules, involved in many physiological processes that are highly controlled [1,2]. Furthermore, their deregulation is often associated with pathologies ranging from cardiovascular and inflammatory disorders to cancer and neurological disorders $[3,4]$. They are therefore very attractive biological targets for the identification and design of pharmacological molecules that can modulate their activity [3]. The literature is full of examples of compounds targeting proteases, which have reached clinical phase and/or placed on the market, illustrating perfectly the considerable interest that is brought to them by the academic and industrial laboratories [3,5] (Table 1). Given not only the success of a number of flagship protease inhibitors in the treatment of hypertension, hepatitis C, or HIV triple therapy [5] but also the lessons learned from the failures [3,7], the interest for synthetic modulators of proteases remains constant [8]. The development of such compounds must then be based on a precise knowledge of their catalytic mechanism and structure [2]. In the body, proteases are subjected to strict regulation. They are often initially secreted as inactive forms or 'zymogenic' precursors, whose cleavage of the $\mathrm{N}$-terminal end allows their activation into mature enzyme. Moreover, direct regulation of the proteases is ensured by endogenous inhibitors which reduce their catalytic activity when this is no longer necessary [9]. This regulation makes it possible to preserve the homeostasis of the numerous physiological systems in which the proteases are involved [10]. More than one-third of human proteases are serine proteases. These are probably the enzymes that are the most studied in detail $[1,2]$. They are characterized by a catalytic serine residue that acts as a nucleophile and are involved in a wide variety of processes such as digestion, development, blood coagulation, fibrinolysis, immune response, prohormone cleavage, signal transduction, and complement fixation [11]. In this review, after the description of the role and features of selected serine proteases in inflammatory diseases, we will give an overview of current patents on serine proteases inhibitors. Particularly, we will place emphasis on their diversity in term of chemical scaffolds and clinical field of application.

\section{Serine protease main features}

In human, serine proteases exert their activities at various cellular levels and are responsible for the coordination of many physiological functions including digestion, cell cycle, coagulation, immunity, and reproduction [2]. Furthermore, serine proteases are key elements of the inflammation response due to their release from activated leukocytes and mast cells or generation through the coagulation cascade $[12,13]$.

The dysregulation of serine proteases is thus involved in a wide range of pathologies: thrombin and plasmin in coagulopathies and bleeding disorders, granzymes and neutrophil 


\section{Article highlights}

- In this review, we focus on the serine proteases involved in inflammatory diseases

- Selected inhibitor patents are reported for the 2011-2016 period with a special emphasis for kallikreins, plasmin and neutrophil elastase

- The inhibitors can be divided in two categories: (i) heterocycles and (ii) peptidic or peptidomimetic entities inspired from substrates or macromolecular natural inhibitors

- The most successful inhibitor group is this of heterocycles that includes: triazoles, benzylamine, benzoxazinones, pyrroles, coumarins.

- Skin inflammatory diseases (Netherton Syndrome, atopic dermatitis, psoriasis, rosacea) and lung inflammation constitute among the most dynamic therapeutical areas within the analyzed time period

- Several preclinical studies on serine protease inhibitors were performed in the context of joint diseases (neutrophil elastase)

- Gl inflammatory diseases (Crohn's disease, ulcerative colitis) are under consideration for the targeting of serine proteases (trypsinlike proteases).

This box summarizes key points contained in the article.

elastases (NEs) in immune deficiencies [12], and plasma kallikreins levels in blood pressure disorders like angioedema [14].

In the epidermis, serine proteases, including some kallikrein-related peptidases that we will detail hereafter and matriptase, are involved in various skin disorders [15-18].

Serine proteases which possess similar structures and catalytic properties are grouped into clans. The four main clans are clan PA represented by chymotrypsin, clan SB by subtilisin, and clans SC and SF which encompass various proteases $[2,19]$.
The specificity of cleavage of a given protease is based on the interaction of a protein or peptide substrate with the residues of the protease at the active site. The surface of the protease that is capable of hosting a side chain of a single substrate residue is referred to as the 'subsite' [20-22]. The subsites are numbered from either side of the cleavage site: $S_{1}-S_{n}$ to the $\mathrm{N}$-terminus and toward $S_{1^{\prime}}-S_{n^{\prime}}$ to the C-terminus of the substrate. The corresponding residues on the substrate are numbered $P_{1}-P_{n}$ and $P_{1^{\prime}}-P_{n^{\prime}}$, respectively $[1,20]$. The structure of the active site of the protease thus determines the nature of the residues of the substrate which can bind specifically to the enzyme [1].

Depending on their specificity for cleaved residues $\left(P_{1}\right)$, serine proteases can be classified as trypsin, chymotrypsin, or elastase analogs. This specificity is guided by the size and nature of the residue involved in the catalytic pocket of the enzyme. Trypsin or trypsin-like (TL) analogs cleave after a positively charged residue (lysine or arginine). Their pocket $\mathrm{S}_{1}$ being narrow, deep, and negatively charged. The $\mathrm{S}_{1}$ pocket of 'chymotrypsin-like (CTL)' is broad and hydrophobic in nature, this results in a specificity for medium or large hydrophobic residues (tyrosine, phenylalanine, and leucine) [21,22]. Elastase-like has a reduced pocket that receives short and uncharged residues [21]. For example, those which have a digestive role, such as chymotrypsin, generally have few requirements with respect to the substrate and a large hydrophobic residue in position $\mathrm{P}_{1}$ is sufficient. The activity of other proteases can be also based on the recognition of a complete peptide portion, such as, enterokinase which requires the binding of an Asp-Asp-Asp-Asp-Lys sequence in the $S_{1}-S_{5}$ subsites to operate properly [23].

Table 1. Selected serine protease inhibitors in the clinic or under clinical trials for different indications.

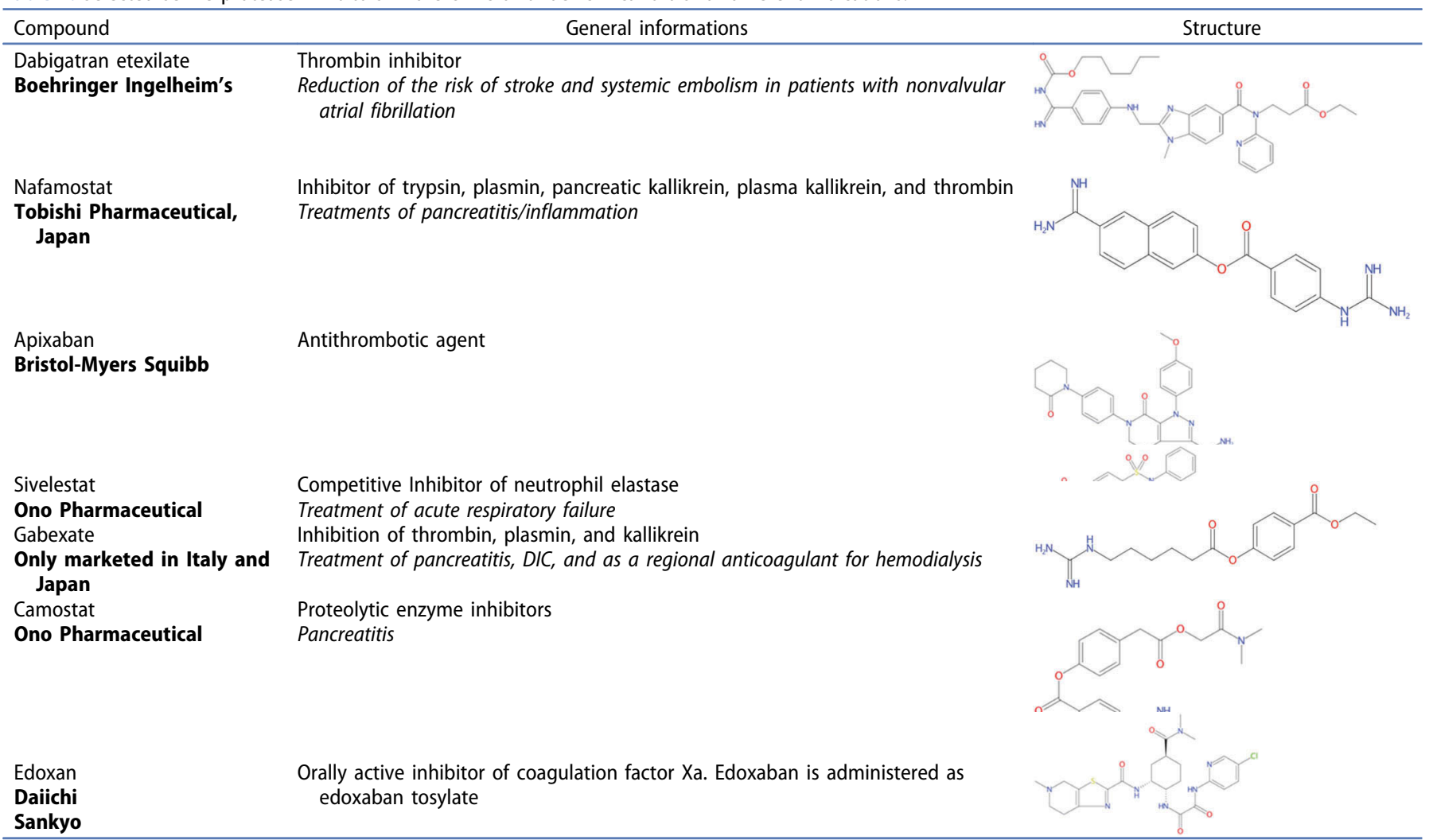

The data were obtained from DrugCentral (online drug Compendium, http://drugcentral.org) [6].

DIC: disseminated intravascular coagulation. 
Various strategies have been employed to design specific substrates. Most serine proteases hydrolyze both ester and amide linkages within a synthetic substrate, where the leaving group is replaced by chromogenic or fluorogenic groups. These substrates do not take into account the specificity of the $S_{n^{\prime}}$ sites, but they are generally preferred in enzymatic assays because of their simple and rapid implementation. They allow continuous measurements with high sensitivity, on the order of picomolar for fluorescence detection. A wide variety of fluorogenic or chromogenic substrates are commercially available, which allows rapid determination of the specificity of $S_{n}$ sites for a given protease [23]. Activity-based probes are useful tools for dissecting out the role and dynamics of proteolytic networks into cells and tissues $[24,25]$. A recent study reported efficient activity-based probes for the monitoring of serine proteases ex vivo in inflammation [26]. Salvesen and coworkers have also proposed a very elegant strategy that provides a toolbox of fluorescent probes for parallel imaging which showed an uneven distribution of serine proteases in neutrophils involved in inflammation [27].

\section{Serine proteases involved in inflammatory diseases a survey}

Inflammation is a classical well-recognized essential step for the control of microbial invasion or tissue injury as well as for the maintenance of tissue homeostasis under various noxious conditions [28-30]. The causes of inflammation are numerous and varied: infectious agent, inert foreign substance, physical agent, posttraumatic cytotoxic injury, etc. Inflammation begins with a 'recognition' reaction involving certain cells of the body (monocytes, macrophages, lymphocytes), or circulating proteins (antibodies, complement proteins, Hageman factor, etc.). The recognition phase follows the sequential activation of a whole set cells and mediators whose order of intervention is complex and variable.
Some mediators, such as prostaglandins and cytokines, are produced by different cell types, act on several cell types, and control sometimes their own production by retroactive regulation. Moreover, inflammation and coagulation constitute two host defense systems with complementary roles in eliminating invading pathogens, limiting tissue damage, and restoring homeostasis [29]. Infection leads to the production of pro-inflammatory cytokines that, in turn, stimulate the production of tissue factor. Conversely, activated coagulation proteases may affect specific receptors on inflammatory cells and endothelial cells and thereby modulate the inflammatory response [30]. Serine proteases are key actors of inflammation responses, both in physiological and pathophysiological contexts [12]. In particular, in the microenvironment of inflammatory tissues, extracellular serine proteases (e.g. human neutrophil elastase [HNE] or kallikrein-related peptidases [KLKs]) can modulate cell signaling via the regulation of proteinase-activated receptors (PARs). PARs (PAR-1, 2, 3, and 4) belong to the superfamily of receptors coupled to G-proteins and are involved in a number of pathways physiological and pathological signaling in a wide variety of tissues [31]. These receptors are irreversibly activated by the action of proteases mainly from the class of serine proteases having a specificity of the TL substrate, cleaving following the arginine or lysine residues. A multitude of works suggest that the mechanism of this cleavage occurs within extracellular domain of the receptor following an arginine or lysine residue, with the generation of a new $\mathrm{N}$-terminus. This unmasked end (tethered ligand) binds as a ligand on the extracellular loops of the receptors causing allosteric changes followed by the coupling of receptors to heterotrimeric $G$ proteins and signal transduction. Biased cleavage namely proteolytic processing outside this region can occur and mediates various cellular responses especially in inflammatory context [32].

In Figure 1, we provide a simplified scheme that introduces the principal serine proteases involved in inflammation and

\section{Tissues} skin, lung, pancreas, heart, stomach, gut, spinalcord, brain
SelectedSerine proteases neutrophilelastase, plasmin, kallikreins

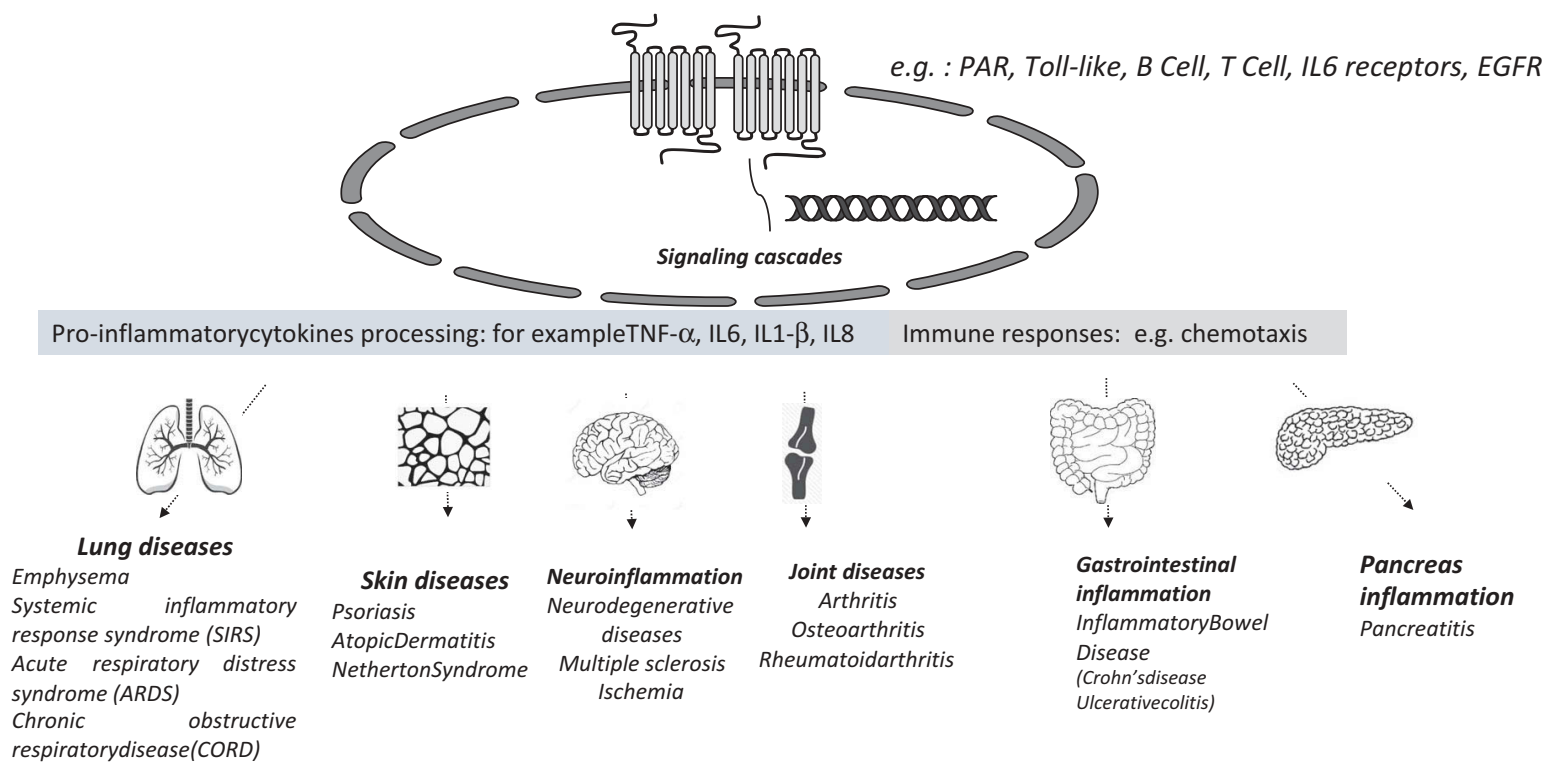

Figure 1. Simplified scheme of the involvement of representative serine proteases in the inflammatory processes and diseases. 
associated diseases for which the search of inhibitors has been validated and is quite active. Briefly, specific cell surface receptors (Toll-like or PARs for example) are activated by serine proteases, which can ultimately prolong or terminate cytokine-induced responses for example. In particular, neutrophil serine proteases have been proposed as proteases that impact cell viability through their caspase-like activity and initiate the adaptive immune response via a direct activation of lymphocytes [33].

A complete survey of the molecular targets is beyond the scope of this review; for the details, the reader could refer to the following outstanding reviews [28-30]. For sake of simplicity and due to huge effort of both academic and pharmaceutical firms to depict pathophysiological pathways and develop therapeutic strategies [3,34], we will mainly focus on skin and lung inflammation. Main features and current focus of in each field are summarized in the next paragraphs.

\subsection{Skin inflammation}

Over the main inflammatory diseases necessitating inhibition of serine proteases, skin inflammation represents a greatly documented area in term of pathogenesis and drug discovery $[17,18]$. Indeed, many pharmaceutical companies have developed active research activity on protease-based skin diseases. The process of skin inflammation is complex and is still not completely understood [35]. When the skin is exposed to exogenous stimuli, such as UV radiation, irritants (such as soaps or fragrances), or to allergens, skin cells produce a variety of inflammatory cytokines and chemokines. These bind to specific receptors on target cells and stimulate the production of additional inflammatory signaling. Some cytokines cause the migration of immune cells from the blood to the skin where they then produce more inflammatory mediators, as well as enzymes, free radicals, and chemicals that damage the skin. Several diseases are emblematic of skin inflammation and involve serine proteases as decisive element in their pathological pathways [17].

Among them, atopic dermatitis (AD) and psoriasis are widespread chronic inflammatory skin disease that both negatively impact life quality. There are characterized by dry, scaly skin, inflammation, and increased permeability of the skin [36-38]. In the past 30 years, the incidence of $A D$ increased by 2-3 times in industrialized countries, it is estimated that the prevalence of $A D$ children reached $11-30 \%$ of children and $2-10 \%$ of adult depending of the population $[39,40]$. The prevalence of psoriasis is approximatively $1-3 \%$ in both children and adults, although it is uncommon before age of 9 $[41,42]$.

AD pathogenesis is complex and not completely understood, but the skin barrier dysfunction has proven to be one of the key factors in the development of AD. Most of the emerging therapeutic strategies to treat AD concern inflammation and/or pruritus due to a broader necessity to target these pathological features [37]. Furthermore, a recent review pointed out the fact that $A D$ and psoriasis are becoming increasingly recognized as systemic rather than localized cutaneous diseases [43]. Indeed, skin inflammation is frequently associated to metabolic cardiovascular and other comorbidities and consequently constitute major financial burden on health-care system. Thus, systemic intervention on both diseases could be of a great interest.

Partial or temporal deregulation of kallikrein activity is one of the main features of cutaneous barrier dysfunction in patients with $A D$ [44]. It has been suggested also that the enhancement of protease activity through increased kallikrein 7 (KLK7) expression by Th2 cytokines IL-4 and IL-13 might be an important factor for mechanical and chemical epidermal barrier dysfunction for patients with AD [45].

Rosacea is another chronic inflammatory condition affecting skin mainly of the central face $[16,46,47]$. Rosacea is a common but underdiagnosed condition of the facial skin that affects around $10 \%$ of all individuals.

Patients with rosacea have been shown to have increased baseline expression of cathelicidin LL37, an antimicrobial peptide key actor of innate immunity, and kallikrein 5 (KLK5). KLK5 was shown to be responsible for the overproduction of LL37; however, the precise molecular mechanisms are still under investigation [48]. This nonnatural production triggers proinflammatory events; LL-37 is processed into even shorter fragments that have been shown to regulate processes, such as leukocyte chemotaxis, angiogenesis, and expression of extracellular matrix components [48-50].

The importance of the regulation of KLKs by their endogenous inhibitors in the maintenance of homeostasis is clearly demonstrated in the Netherton syndrome [51-53]. The Netherton syndrome is a rare genetic disease $(1 / 100,000$ newborns) of very serious gravity. It is characterized by severe ichthyosis that compromises the vital prognosis of newborns due to a mutation in the SPINK5 gene encoding the macromolecular protease inhibitor LEKTI, which then loses its regulatory function of serine proteases, in particular KLK5, 7, and 14 [52,54-58]. The upheaval of the kallikrein-macromolecular inhibitor equilibrium is also involved in some forms of psoriasis and common eczema [59,60].

Currently, there is no specific therapy for Netherton Syndrome (NS) but only palliative treatments for management of skin infections, reduction of itching, and pain. It has been recently demonstrated that unregulated activities of KLK5 and KLK7 are responsible for NS development and both proteases should become targets for NS therapy [61].

\subsection{Airway inflammation}

Lung inflammation is associated with wide set of diseases and still represent a real challenge to public health. The airway epithelium is indeed the first site of contact with inhaled agents. Its epithelial cells secrete a variety of substances such as mucins, defensins, lysozyme, lactoferrin, and nitric oxide, which nonspecifically shield the respiratory tract from microbial attack [62].

Inflammation is an important feature of many pulmonary diseases such as pneumonia, ARDS (acute respiratory distress syndrome), asthma, and COPD (chronic obstructive pulmonary disease) [63]. For example, COPD is a global epidemic, affecting nearly 300 million people worldwide and killing 3 million individuals each year. It is the only major cause of mortality that is increasing such that by 2030 the mortality rate will 
reach 7-8 million per annum. COPD which mainly affects cigarette smokers is characterized by lung inflammation, which intensifies with disease progression. Proteolytic enzymes have a prominent role in particular in the emphysematous phenotype [64]. Varied and disparate strategies have been adopted to intervene in pulmonary immune responses. In addition to looking at the cytokines, cytokine receptors, and cell-surface molecules, cellular signal transduction and gene activation have been targeted for therapy [63]. Neutrophil proteases especially HNE have been early investigated as therapeutical target of prime importance in the above cited lung diseases [65].

\subsection{Gastrointestinal inflammation}

Gastrointestinal inflammation (Gl) is an immune response in the digestive tract that can induce symptoms like nausea, cramping, and diarrhea. Among associated diseases, gastritis, esophagitis, and colitis represent preeminent disorders. Inflammatory bowel disease (IBD) is a group of inflammatory conditions of the colon and small intestine for which intensive researches are performed to find therapeutical issues [66]. Crohn's disease (CD) and ulcerative colitis (UC) are most representative forms of IBD. It is estimated that 1.5 million in North America and 2.5 million persons in Europe have IBD. The peak incidence of $C D$ and $U C$ is between 20-30 years and 30-40 years of age, respectively. Their incidence and prevalence are similar across males and females [67]. Gastrointestinal tract constitutes the most exposed organ of the body to proteases in both physiological and pathological contexts both in lumen and deeply in the tissues. Specific proteases including serine proteases (NE, trypsin, chymotrypsin) are constitutively expressed at low levels in the healthy human gut and play an essential protective role in the regular turnover of gut barrier components and in the physiological migration of immune and nonimmune cells within the mucosa $[68,69]$. Conversely, during intestinal inflammation, some proteases are induced and are expressed at higher levels, dysregulated proteolysis subsequently leads to both structural and functional changes in the mucosal barrier, which in turn can result in the amplification of the inflammatory process $[66,69]$.

In particular, the upregulated production of proteases, including MMP (Matrix Metallo-Proteinase)s, NE, and cathepsins has been reported in IBD. Tryspsin-like activity was also shown to be upregulated in IBD (especially in CD and UC). Moreover, activation PAR receptors are known to be involved in a various set of gut physiological functions including, ion exchange, permeability, etc. The involvement of PAR receptors in GI inflammatory diseases has also been depicted for IBD; indeed, proteases promote inflammation via the activation of cytokines and chemokines pro-inflammatory properties, by remodeling extracellular matrix to facilitate neutrophil infiltration. Like in the context of skin disorders and lung inflammation, disequilibrium between proteolytic activity and antiprotease expression is observed in GI inflammatory diseases. Therefore, a therapeutical option would be to re-equilibrate this protease-antiprotease unbalance. However, although considered as a valuable strategy to treat Gl disorders, development of protease inhibitors still needs the identification of hot targets to allow specific action. Namely proteases from the microbiome would constitute ideal targets [70]. Moreover, the importance of serine protease inhibitors in the search for new treatments for abdominal pain in postinflammatory irritable bowel syndrome patients has been recently demonstrated. A complete reversal of the hypersensitivity was achieved with the newly developed tryptase/ matriptase inhibitor SPIx but not with the broad-spectrummarketed serine protease inhibitor (nafamostat mesylate) underlining the importance of being selective [71]. In another murine model, namely chronic colitis transfer model, it has been established that inhibition of serine proteases lead to a decrease of the development of the experimental colitis by a downregulation of pro-inflammatory cytokines (TNF-a, IL-1, IL6) [72]. Despite the increasing interest, no significant patents dealing serine proteases inhibitors to treat GI inflammatory diseases have been identified within the investigated period.

\section{Main features of the selected inflammatory serine proteases}

From an exhaustive survey both of the literature and published patents, it appears that three main serine proteases/ class of serine proteases are subjected to an increased interest for the development of inhibitors in the context of diseases with a major inflammatory component. Namely, kallikreins and kallikrein-related peptidases, NE, and to a lesser extent plasmin (often associated to plasma kallikrein or kallikrein-related peptidases in various disease contexts) constitute privileged targets for the development of drugs and/or chemical probes for diagnosis. We will thus focus the purpose of the present review on patents relative to these latter serine proteases.

\subsection{Kallikreins and kallikrein-related peptidases}

Among the relatively new serine proteases, 'tissue' kallikreins or kallikrein-related peptidases - as distinct from 'plasma' kallikrein - form a family of proteases present in at least six orders of mammals. In humans, tissue kallikreins (KLKs, hKLKs, or hKs for human kallikreins) are coded by 15 structurally similar genes (KLK) which co-locate in tandem on chromosome 19q13.4, thus representing the largest cluster of contiguous protease genes in the human genome [73-75]. They include human kallikrein KLK1 and the other 14 kallikrein-related peptidases (KLK2-KLK15). The first member of this family, KLK1, was characterized in the pancreas almost a century ago and named 'kallikrein' in reference to

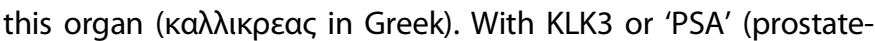
specific antigen), discovered in the 1960s, and KLK2, whose gene was isolated in the 1980s, KLK1 belongs to the subfamily of 'classical kallikreins.' These 3 proteases are more closely related to each other than the 12 'new kallikreins' KLK4-15 whose progressive assignment to the KLKs family only began in the late 1990s. Thus, the KLKs family was best known for the role of KLK1 in the kallikrein-kinin system or for the use of KLK3 or 'PSA' (and, to a lesser extent, KLK2) as a biomarker in screening for prostate cancer. However, during the last decade, great progress has been made in understanding the cellular and tissue localization and in vivo logical physio(patho) regulation of most KLKs $[76,77]$. Significant new functional concepts have therefore emerged 
following the development of animal models with selectively modified kallikreins (or endogenous inhibitors) and the identification of individuals with natural KLKs deficiencies. Kallikreins and kallikrein-related peptidases are now well known for their involvement in renal function, desquamation, dental enamel formation, reproduction, synaptic plasticity, and cerebral function $[4,78]$. At the same time, the importance of fine regulation of their in vivo activity has become evident as with all proteases. Their activity is thus modulated by mechanisms and regulatory factors similar to those of serine proteases such as their cascade activations, their microenvironment, and their endogenous inhibitors. Thus, the loss of tissue-specific regulation of kallikreins has been linked to various conditions including respiratory diseases, neurodegeneration, anxiety, schizophrenia, skin barrier dysfunction, inflammation, and cancer. A recent study from Lizama et al. has experimentally confirmed for the first time the presence of kallikrein-related peptidases in the human neutrophil [79]. It has been particularly shown that a kinin B1 receptor agonist induces the secretion of KLK1, KLK6, KLK10, KLK13, and kallikrein 14 (KLK14) with similar amounts as those induced by the wellknown chemotactic peptide (f-Met-Leu-Phe). Thus, secretion of KLKs to the inflammatory milieu, induced either by kinins or other pro-inflammatory mediators, leads to human neutrophils with an enhanced enzymatic capacity that may be relevant in certain human disorders.

Plasma kallikrein proteolytically cleaves high molecular weight kininogen to generate the potent vasodilator and pro-inflammatory peptide, bradykinin [80]. Unregulated plasma kallikrein activity is responsible to excessive and potentially fatal edema like hereditary angioedema (HAE) with C1-inhibitor deficiency for example [80,81]. Therapeutical and as diagnostics tools, sufficiently selective inhibitors of plasma kallikrein were generated [82].

This association with pathologies has contributed to the development of numerous pharmacological studies focused on the development of specific modulators - mainly inhibitors - of kallikreins as potential therapeutic agents $[4,83]$. These efforts were all the more important with the recent characterizations of the three-dimensional crystallographic structures of most kallikreins and the elucidation of their substrate specificities $[84,85]$.

\subsection{Neutrophil elastase}

Neutrophils, key immune cells for protection against microbial infection, are also associated with a range of pathologies, including auto-inflammatory diseases, such as systemic lupus erythematosus and psoriasis [86,87]. Neutrophil infiltration is a common pathological feature in acute inflammatory diseases. Furthermore, neutrophils are a rich source of proteolytic enzymes, including serine proteases and their inhibitors involved in neutrophil programmed cell death pathways [88].

Four active serine proteases, NE, cathepsin $\mathrm{G}$, proteinase 3, and neutrophil serine protease 4 , as well as azurocidin, an enzymatically inactive serine protease homolog, were characterized in neutrophils $[33,89]$. HNE belongs to chymotrypsin family of serine proteases stored in the azurophil granules of the neutrophil cytoplasm. Very efficient HNE contributes to many biological processes that necessitate structures breakdown, such as dynamics of extracellular matrix and tissue remodeling (elastin, collagens), host defense by the disabling of bacterial invasion (cell wall proteins), and in initiation steps of inflammation $[90,91]$. Indeed, HNE is a key regulator by its intervention in the activation of bioactive proteases like MMPs, release of growth factors, shedding of cell-surface-bound receptors, and degradation of endogenous proteases inhibitors or virulence factors $[65,92]$. The activity of HNE is tightly regulated by compartmentalization in storage granula and phagolysosomes, as well as by the intervention of endogenous serine proteases inhibitors such as SERPINs (a-1 antitryspin e.g.). Unopposed activity of HNE is implicated in the onset and progression of many inflammatory diseases especially of the cardiopulmonary system such as lung emphysema, COPD, pulmonary arterial tension, and pulmonary fibrosis. Various rodent knockout models modulating either HNE or antiprotease expression revealed a significant decrease of phenotypic aspects of pulmonary diseases like emphysema. Elastase knockout mice are particularly sensitive to bacterial infection especially with Gram negative bacteria [93]. Thus, HNE constitutes an attractive target for drug discovery in pharmaceutical industry by developing inhibitors $[86,94]$. Despite, the importance of HNE in the clinic (see cited pathologies), only few inhibitors reached the clinic. Only few chemical scaffolds showed profiles suitable for clinical development. The first potent HNE inhibitors to reach clinical investigations were biologicals such as Elafin (tiprelestat) [95]. Among small-molecules inhibitors, one can cite compounds bearing electrophilic properties like serine acylator sivelestat $[96,97]$ or transition state analog such as freselestat [98]. Therapeutic inhibition of HNE holds promise with powerful treatment effect in various preclinical models of lung, bowel and skin inflammation, and ischemia-reperfusion injury relevant to myocardial infarction, stroke, and transplant medicine [87]. Furthermore, Sivelestat significantly attenuated LPS (LipoPolySaccharides) -induced acute lung injury (ALI) during recovery from neutropenia [99]. These findings suggest that HNE inhibition could be a promising way of decreasing lung inflammation without increasing susceptibility to infection in ALI/ARDS during neutropenia recovery. Recently, phase II studies are in progress by the AstraZeneca firm on a reversible inhibitor AZD9668 (alvelestat) for patients with pulmonary diseases $[100,101]$.

Apart from lung inflammation, NE is also involved in joint disorders like arthritis. NE and PAR2 were shown to contribute significantly to the development of joint inflammation, pain, and peripheral neuropathy associated with experimental osteoarthritis, suggesting their potential as therapeutic targets [102-104]. Indeed, pharmacological inhibition using wellknown sivelestat and knockout of NE suggest that its implication is mediated by cleavage of PAR2 and appear to involve activation of a p44/42 MAPK pathway [103].

\subsection{Plasmin}

Plasmin (Pla) is a tryptic serine protease that is essentially associated to the fibrinolytic system as an essential effector via its key involvement in fibrin degradation and clot removal [105]. Plasmin can be generated at the cell surface by activation of plasminogen that binds to its receptors which are abundantly expressed. This localized plasmin generation is 
necessary both in physiological processes and some diseases like chronic inflammation and tumor metastasis. Plasmin is a 2-chain protein composed of an N-terminal heavy chain of 561 residues forming 5 kringle domains and a C-terminal light chain of 230 residues that constitutes the catalytic domain $[106,107]$. Although displaying structural homology with trypsin, plasmin is characterized by a striking differences that may be responsible for the modulation of its substrate repertoire $[108,109]$. Plasmin lacks residues from 95 to 100 (chymotrypsinogen numbering), these residues form a $\beta$-hairpin in most of the serine proteases which result in more open active sites [110]. This structural specificity allows the design of specific inhibitors, including noncompetitive and allosteric inhibitors $[108,109]$. In various cases, either in natural or man-made (surgery) hemostatic deregulation, bleeding complications are very common and can be alleviated by reducing plasmin generation and activity $[107,111,112]$.

A growing number of studies state important roles of plasmin in the modulation of immunological processes by direct interaction with various cellular types such as leukocyte, vascular cells, or other soluble factors of the immune system [112]. While major physiological functions are related to the removal of misfolded proteins and tissue homeostasis, a large body of evidence associate excessive plasmin generation from plasminogen to acute and chronic inflammatory processes [112]. New findings suggest that Plg/Pla regulate several key steps in inflammation resolution, namely neutrophil apoptosis, macrophage reprogramming, and efferocytosis, which have a major impact on the establishment of an efficient resolution process [111]. Recently, it has also been shown that plasmin regulates the influx of inflammatory cells and the production of inflammatory cytokines/chemokines [111,112]. Plasmin was also identified as a decisive checkpoint in the inflammatory response during macrophage activation syndrome (MAS) and a potential novel therapeutic target for MAS [113].

Despite a wide range of pathologies where plasmin activity is dysregulated, only few medicines are in the clinic and are mainly indicated in the context of antifibrinolytic therapy [114]. The two main compounds are tranexamic acid and $\varepsilon$-aminocaproic acid, these are lysine analogs that compete with fibrin to bind lysinebinding sites in the kringle domains of plasminogen. These two molecules, although of reference in the treatment of coagulopathies, suffer from lack of specificity due to the multiplicity of lysine sites and adverse effects such as risk of seizure and renal dysfunction [115]. Depending on the clinical applications, an appropriate spatiotemporal control of the inhibition may be necessary, for example regulators of fibrinolysis would benefit of a short half-life time and a rapid elimination [116,117]. To achieve this goal, an exhaustive comprehension of structural features of plasmin is mandatory to propose diverse drug design strategies and to reach a good specificity profile.

\section{General considerations for serine protease inhibitors design}

Depending on the pathology associated with the deregulation of a serine protease, covalent or non-covalent inhibitors may be considered. Although the field of research around serine proteases is very active, most of the studies still remain limited to the identification natural substrates, inhibitors, or physiological functions. Only few serine proteases - such as thrombin or factor $\mathrm{X}$ of the coagulation cascade - have entered the arena of clinical development $[3,5,34]$. Several inhibitors of these few proteases are already used in particular as anticoagulants and antiinflammatory properties (Table 2). Serine proteases especially TL proteases exhibit similar tridimensional fold especially in the vicinity of the substrate binding pocket which encompasses the conserved catalytic triad (His97-Asp102Ser195). There is a rich set of tridimensional structures available in the Protein Data Bank (https://www.rcsb.org/ $\mathrm{pdb} /$ home/home.do) which allow to propose various drug design strategies, especially by targeting specific pockets [8].

In the pharmacological literature, the dominant opinion is that the unopposed activity of these proteases is a factor that accelerates the spread of pathologies and the current approach consists in targeting them by developing inhibitors. However, it is essential to find the right balance in modulating their activity in order to avoid possible damaging side effects. Given the irreversible nature of the action of serine proteases, it is not surprising that several endogenous mechanisms are used to control their activity in the organism [131]. When this activity is deregulated, exogenous modulators can be designed in a therapeutic or diagnostic strategy or simply to better probe the functioning of a given protease. The design of inhibitors is based on both principles of thermodynamics (non-covalent interactions) and chemical reactivity (formation of one or more transient or definitive chemical bonds). In 1992, Krantz proposed a general classification of inhibitors by considering the criterion of reversibility of the inhibitory action [132]. Two categories are therefore considered, so-called reversible inhibitors and socalled irreversible inhibitors. Each of these two categories is characterized by several subgroups.

Reversible inhibitors include two types of inhibitors forming non-covalent complexes with the targeted enzymes. Substrate analogs, which are molecular entities that reproduce the main structural characteristics of the substrate but are not transformed by the enzyme, are counted. The other group is represented by transition state analogs, differentiated from substrate analogs by their structural similarities to the ground state with one of the transition states encountered during the catalytic process. Thus, the affinity of these inhibitors to the enzyme is much higher than that observed for the substrates. These inhibitors are therefore commonly referred to as 'high-affinity inhibitors' or 'tight-binding inhibitors.' Irreversible inhibitors are subdivided into five groups and are characterized by the formation of covalent bonds between the enzyme and the inhibitor, which can lead to the formation of a definitive or transient covalent complex. In the latter case, the enzyme is reactivated more or less slowly.

\section{A selection of recent patents on serine proteases inhibitors}

In summary, several categories of inhibitors were reported including those of protein nature like natural protein-based inhibitor and antibodies. However, chemical scaffolds are far from being the most numerous inhibitors reported during the 


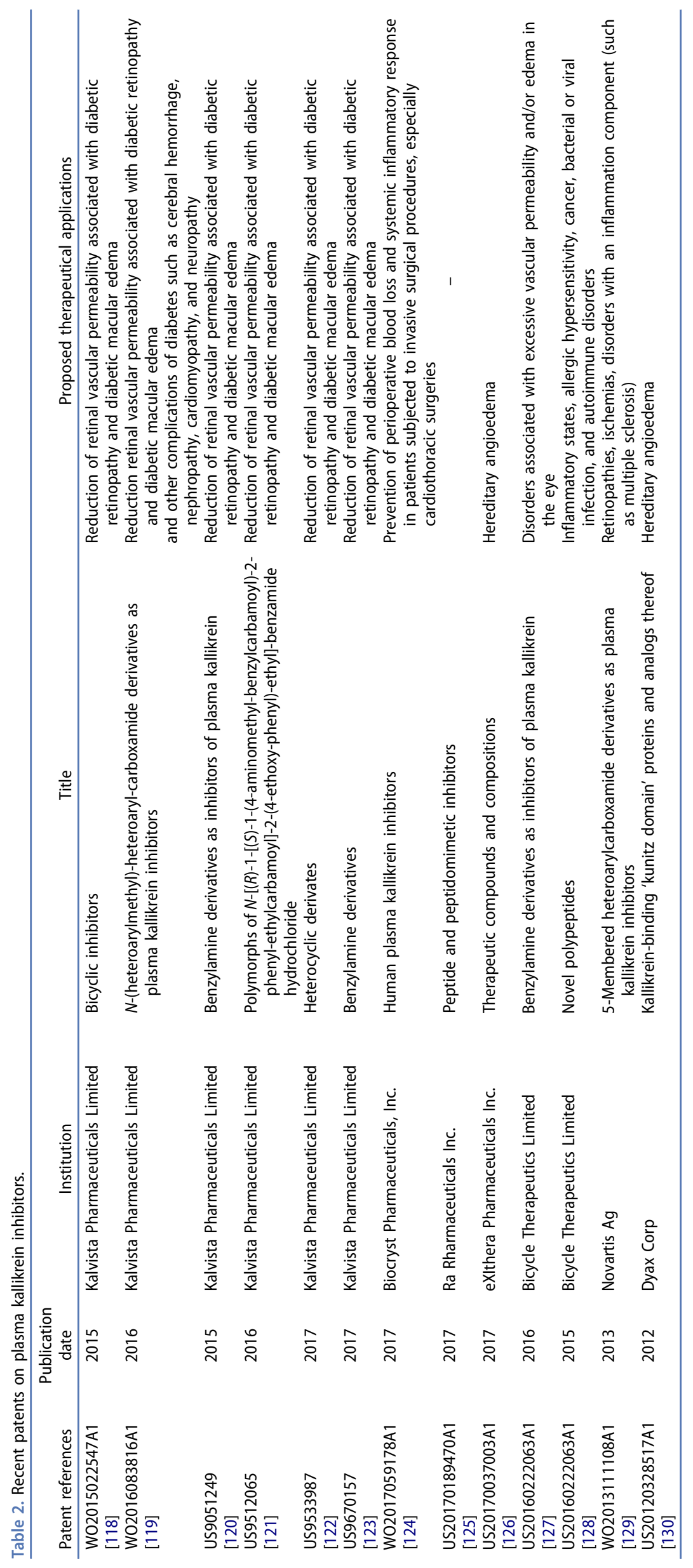


investigated period, they mainly include triazoles, quinazolines, coumarins, and pyrroles. To allow a useful reading, selected inhibitors will be introduced target by target.

\subsection{Tissue and plasma kallikreins inhibitors}

\subsubsection{Plasma kallikrein}

Plasma kallikrein is a well-established target in particular in HAE attack for which several compounds have been developed. Plasma kallikrein plays an important role in a variety of physiologic processes, including, but not limited to, blood pressure regulation, the contact activation pathway of blood coagulation, fibrinolysis, inflammation, and pain. Therefore, targeting plasma kallikrein offers novel strategies not previously explored to interfere with thrombosis and vascular inflammation in a broad variety of diseases [133-135]. Table 2 gathers the most recent patents on PK inhibitors, the majority of them are from private companies. The selected chemical structures are reported in Figure 2. Kalvista Pharmaceuticals was particularly very efficient in term of diversity of chemical scaffolds, including bicyclic [118], $\mathrm{N}$-(heteroarylmethyl)-heteroaryl-carboxamide derivatives [119], benzylamine derivatives [123], and heterocyclic derivatives [122].

The bicyclic derivatives were addressed to various therapeutic applications, particularly in the treatment of impaired visual acuity, diabetic retinopathy, macular edema, HAE, diabetes, pancreatitis, cerebral hemorrhage, nephropathy, cardiomyopathy, neuropathy, IBD, arthritis, inflammation, septic shock, hypotension, cancer, adult respiratory distress syndrome, disseminated intravascular coagulation, cardiopulmonary bypass surgery, and bleeding from postoperative surgery [118]. The benzylamine derivatives were developed in particularly for the treatment of retinal vascular permeability associated with diabetic retinopathy and diabetic macular edema. Figure 2 shows general structure of benzylamine as well as the two most potent inhibitors $\left(\mathrm{IC}_{50}=1-2 \mathrm{nM}\right)$ (1-[4-(4-methylpyrazol-1-ylmethyl)-benzyl]-1H-pyrazole-4-carboxylic acid 4aminomethyl-2-methyl-benzylamide and $N$-\{[4-(aminomethyl)3-fluoro-2-methylphenyl]methyl\}-1-(\{4-[(4-methyl-1H-pyrazol1-yl)methyl]phenyl\}methyl)-3-(trifluoromethyl)-1H-pyrazole-4carboxamide). These compounds were found very selective toward PK, pharmacokinetics studies have also been performed with the best compounds at doses from 9 to $12 \mathrm{mg} /$ kg. PK parameters were for $T_{\max }(150-300 \mathrm{~min})$ and 60-230 ng/ml for $C_{\max }$ [123].

On 11 August 2016, BioCryst announced that it dosed the first subject in the APeX-1 clinical trial of BCX7353 for the oral treatment of HAE. APeX-1 is a two part, phase II, randomized, double-blind, placebo-controlled dose-ranging trial to evaluate the safety, tolerability, pharmacokinetics, pharmacodynamics, and efficacy of BCX7353 as a preventative treatment to eliminate or reduce the frequency of angioedema attacks in HAE patients. Up to approximately 50 eligible subjects with HAE will be enrolled in the study [137]. Novartis and Boehringer Ingelheim International $\mathrm{GmbH}$ have developed five-membered heteroarylcarboxamide derivatives [129]. In another hand RA PHARMACEUTICALS Inc., introduced novel peptides and peptidomimetics inhibitors whether cyclic or linear with improved therapeutical characteristics [125]. On the other hand, Bicycle Therapeutics Limited reported new design of cyclic peptides with improved stability and selectivity [128].

\subsubsection{Kallikrein-related peptidases}

Table 3 summarizes the main patents related to therapeutical inhibitors of kallikrein-related peptidases and Figure 3 the most promising chemical scaffolds. Several diseases are emblematic of skin inflammation and involve serine proteases in their pathological pathways, AD, rosacea, acne, psoriasis, and Netherton syndrome [17]. In all these disorders, inhibition of kallikreins 5 and 7, and possibly KLK14, constitutes an innovative way to treat these skin diseases.

We have previously identified the inhibitory properties of coumarin-3-carboxylate derivatives against these enzymes $[146,138]$. Our small collection of these versatile organic compounds was enriched by newly synthesized derivatives in order to obtain molecules selective against one, two, three enzymes, or acting on all four. We evidenced a series of compounds with $\mathrm{IC}_{50}$ values in the nanomolar range. A suicide mechanism was observed against KLK7 whereas the inactivation was either definitive (suicide type) or transient for kallikreins 5 and 14, and matriptase. Most of these potent inhibitors were devoid of cytotoxicity toward healthy human keratinocytes. In situ zymography investigations on skin sections from human KLK5 transgenic mouse revealed significant reduction of the global proteolytic activity by several compounds.

Kallikrein-related peptidase 4 (KLK4) is implicated in cardiovascular diseases, cancer, endocrino-logical diseases, metabolic diseases, gastroenterological diseases, inflammation, hemato-logical diseases, respiratory diseases, neurological diseases, reproduction disorders, and urological diseases [144]. The invention of Joossens et al. relates to novel compounds and probes which have potent inhibitory activity against KLK4 and/or may be used for the detection of KLK4 peptides and their activity. The compounds of the invention are characterized by the presence of a diphenyl phosphonate group also called warhead a phenyl-guanidine group, and a tail also referred to a linker encompasses a heteroatom. This combination allows an unexpected potency and selectivity KLK4 inhibitory activity. The heteroatom within the tail modulates strongly the selectivity of the inhibition toward a panel of proteases, namely the incorporation of a heteroatom separated at least for 4 atoms to the nitrogen attached to $R_{3}$ (optimum for inhibition 4-9 atoms). Some compounds are irreversible inhibitors with $\mathrm{IC}_{50}$ value lower than $100 \mathrm{nM}$ and inactivation potency up to $10^{2} \mathrm{M}^{-1} \mathrm{~s}^{-1}$.

The use of substituted 3,1-benzoxazin-4-ones as selective inhibitors of human skin kallikreins especially human KLK7, human KLK5, and human KLK14 for the treatment of inflammatory skins diseases, especially Netherton syndrome, has been reported [145]. Only compound 1 (6-ethoxy-7-methoxy2-(2-methylsulfanylphenyl)-3,1-benzoxazin-4-one) and compound 2 (2-(2-chlorophenyl)-6-ethoxy-7-methoxy-3, 1-benzoxazin-4-one) were found to have the desired selectivity, i.e. bearing an $\mathrm{IC}_{50}$ below $0.1 \mu \mathrm{M}$ for $\mathrm{KLK} 7$, an $\mathrm{IC}_{50}$ below $1 \mu \mathrm{M}$ for KLK5 and KLK14, and an $\mathrm{IC}_{50}$ above $10 \mu \mathrm{M}$ for the other proteases tested. The routes of administration proposed for 


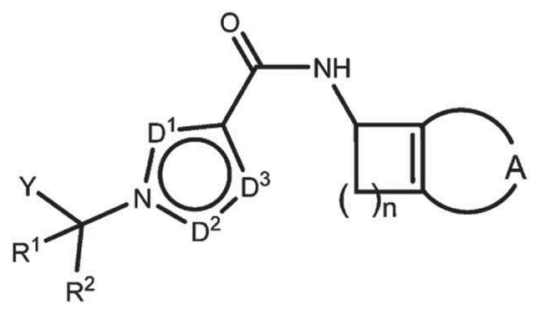

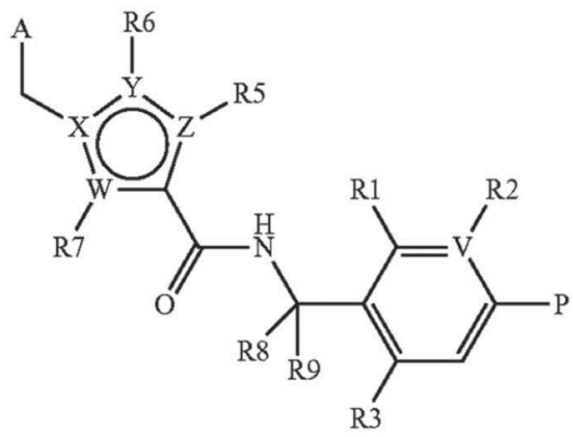<smiles>Cc1cnn(Cc2ccc(Cn3cc(C(=O)NCc4ccc(CN)cc4C)cn3)cc2)c1</smiles>

a.

$I C_{50}=1-2 n M$,<smiles>Cc1cnn(Cc2ccc(Cn3cc(C(=O)NCc4ccc(CN)c(F)c4C)c(C(F)(F)F)n3)cc2)c1</smiles>

b. 5-membered heteroarylcarboxamide derivatives

WO 2017072020 A1 [159]<smiles></smiles>

5-membered heteroarylcarboxamide derivatives

WO 2013111108 A1

[127]
Benzylamine derivatives US9670157

[124]<smiles>[R]Nc1ccc(C)c(C(C)C(=O)O)c1[R]</smiles>

Peptides and peptidomimetics US20170189470A1 [128] 


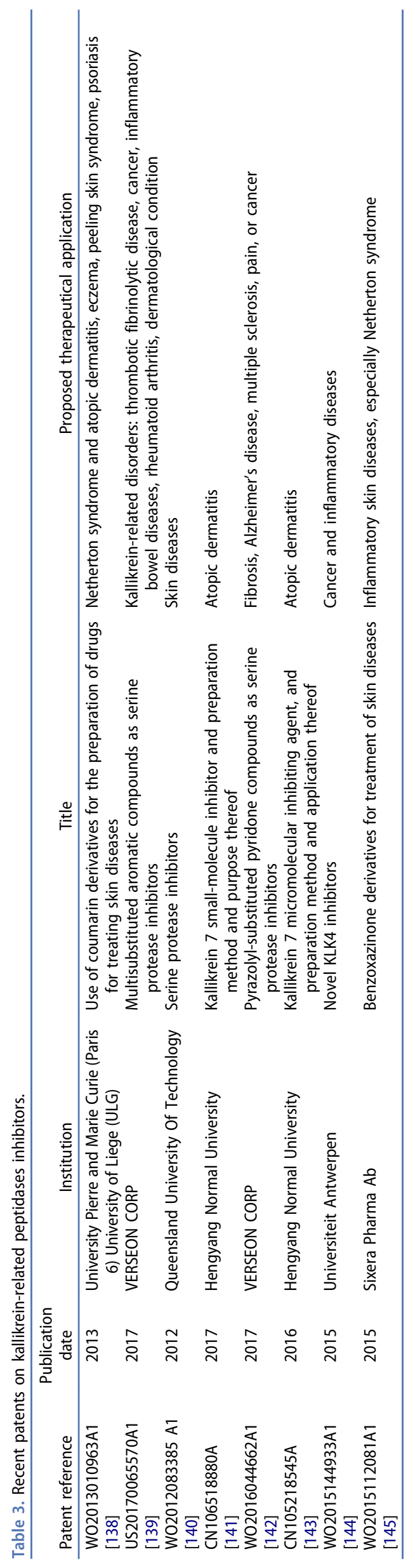

these lead compounds vary from oral to subcutaneous, dosage will be adapted to the severity of the disease and the age of the patient. Interestingly, in 2008, Koistinen et al. had already identified benzoxazinone compounds as KLK3 inhibitors with submicromolar inhibitory concentrations [147].

SFTI (sunflower trypsin inhibitor) derivatives were engineered [148] (Figure 3). These inhibitors are developed to target KLK14, KLK7, and/or KLK5 protease inhibitors and their uses in the diagnosis, prevention, or treatment of a skin disease or pathology, or other undesirable skin condition [140]. $R^{1}, R^{2}, R^{3}, R^{4}, R^{6}$, and $R^{8}$ are each an amino acid residue, $R^{5}$ is an amino acid residue other than Phe, and $R^{7}$ is an amino acid residue other than Asp or Glu. In one embodiment, $R^{1}$ is Trp or Tyr, $R^{2}$ is Val or He, $R^{3}$ is Arg, $R^{5}$ is $G l n$, and $R^{7}$ is Asn. There is no limitation on natural amino acids; however, unnatural ones' amino acids include, without limitation, allyl glycine (AllylGly), biphenylalanine (Bip), citrulline (Cit), 4-guanidinophenylalanine (Phe(Gu)), homoarginine (hArg), homolysine (hLys), 2napthylalanine (2-Nal), ornithine (Orn), and pentafluorophenylalanine (FsPhe). SFTI-WCVR F12 N14 was the most selective variant: complete inhibition of KLK14 was achieved with $2.5 \mu \mathrm{M}$ inhibitor, with very weak effect on KLK5, trypsin, and matriptase. SFTI-YCVR F12 N14 was also relatively selective inhibitor of KLK14 with an IC $501.75 \mu \mathrm{M}$ inhibitor, with no effect seen on KLK5, trypsin, and matriptase. An ex vivo skin desquamation was performed and it has been shown that SFTI-WCVR Q12 N14 inhibits KLK14-mediated desmosome remodeling in these assays at two doses (1.75 and $3.5 \mu \mathrm{M})$. More precisely, SFTI-WCVR Q12 N14 attenuates KLK14mediated cell detachment by inhibiting proteolysis of desmoglein-1, bringing thus the proof of concept that inhibiting KLK14 would be of a great interest in skin diseases involving epidermis disruption.

\subsection{NE inhibitors}

Serine proteases are attractive targets for the design of enzyme inhibitors, since they are involved in the etiology of several inflammatory diseases (Figure 4). Within the class of serine proteases, $\mathrm{HNE}$ is among the most destructive enzymes in the body. BAY 85-8501 a modern inhibitors that bind HNE via an induced fit with a frozen bioactive conformation leading to a significant increase in potency, selectivity, and stability, was recently identified [150]. These fifth-generation inhibitors ('pre-adaptive pharmacophores') might succeed in reestablishing the protease-antiprotease balance in patients for the first time [86]. Table 4 compiles the main patents related to HNE inhibitors to treat inflammation in pulmonary diseases. A very recent patent deals with the use of already established selective inhibitors of HNE, Sivelestat, Elastatinal, ONO-681 8, BAY 85-8501, SSR 69071, Alvelestat in the diagnosis, prognosis, prevention, and/or treatment of neuropathic pain as well as chronic pain states harboring a neuropathic component [158].

Elafin reverses obliterative changes in pulmonary arteries via elastase inhibition and caveolin-1-dependent amplification of BMPR2 signaling [160]. Proteo's biopharmaceutical has developed drug candidate Elafin identical to the human antiinflammatory protein elafin. It is a potent inactivator of tissue 
<smiles>[R1]c1cc2cc(C(=O)C([R2])(C)C)c(=O)oc2cc1[R1]</smiles>

\section{Coumarins}

Nanomolar suicide inhibitors of KLK7

[131]<smiles>[R3]NC(c1ccc(NC(=N)N)cc1)P(=O)(Oc1ccc([R])cc1)Oc1ccc(Br)cc1</smiles>

Diphenyl phosphonate derivatives WO 2015144933 A1

[132]

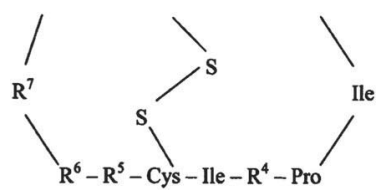

Cyclic peptide derivatives of SFTI [136]

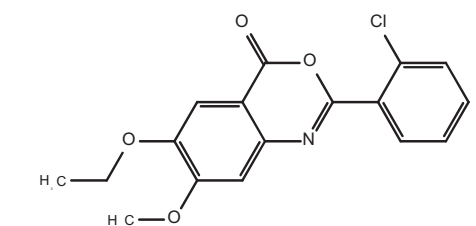

2-(2-chlorophenyl)-6-ethoxy-7-methoxy-3, 1 - benzoxazin-4-one<smiles>CCOc1cc2c(=O)oc(-c3ccccc3SC)nc2cc1OC</smiles>

6-ethoxy-7-methoxy-2-(2-methylsulfanylphenyl)-3 , 1 -benzoxazin-4-one

Benzoxazinones

WO 2015112081 A1

[133]

Figure 3. Chemical scaffolds and patent references of selected kallikrein-related peptidases inhibitors. (a) Coumarins nanomolar suicide inhibitors of KLK7, Ref [138]. (b) Cyclic peptide derivatives of SFTI, Ref [140]. (c) Diphenyl phosphonate derivatives, Ref [144]. (d) Benzoxazinone derivatives, Ref [145].

destroying NE and proteinase-3 and was well tolerated in three randomized, double-blind, placebo-controlled clinical trials. Elafin's ability to block tissue destroying proteases makes it a promising drug e.g. for the prevention and treatment of tissue damage in the course of major surgery, pulmonary diseases, and organ transplantation [159].

Substituted bicyclic dihydropyrimidinones were also identified as HNE inhibitors by Boehringer Ingelheim International $\mathrm{GmbH}$ [154]. These inhibitors were developed for pharmaceutical compositions and methods as agents for treatment and/ or prevention of pulmonary, Gl and genitourinary diseases, inflammatory diseases of the skin and the eye and other autoimmune and allergic disorders, allograft rejection, and oncological diseases. A wide selection of compounds displayed a potent inhibition power, with good selectivity profiles and satisfactory pharmacokinetic parameters. The patent did not show a consensual structure-activity relationship; however, various lead compounds are proposed for further preclinical investigations.

Substituted 4-pyridones and their use as inhibitors of NE activity were also synthetized by the same firm for treatment and/or prevention of pulmonary, Gl and genitourinary diseases, inflammatory diseases of the skin and the eye and other autoimmune and allergic disorders, allograft rejection, and oncological diseases [149]. Some derivatives of the latter invention exhibited favorable pharmacokinetic properties.
When looking at the general structure, A is preferably a phenyl or a five- or six-membered, aromatic heteroring, wherein one, two, or three elements are replaced by an element selected independent from each other from the group consisting of $\mathrm{N}$, $\mathrm{O}, \mathrm{S}$, and $\left(0^{\sim} \mathrm{N}^{+}\right)$.

Tetrahydrotriazolopyrimidine derivatives were also reported by the firm Chiesi Farmaceutici S.p.A. [153]. IC $C_{50}$ below $20 \mathrm{nM}$ was measured for around 30 derivatives; however, no clear structure-activity relationship was deduced from the compound libraries. These compounds were disclosed for use useful in the treatment of diseases or conditions in which HNE activity plays a part. Novel compounds as triazolinone derivatives have also been designed [156]. These compounds protected by the patent are proposed for the treatment of pulmonary disorders such as for example COPD or emphysema.

\section{Concluding remarks}

Inflammation can be at the same time a major hallmark of many diseases as well as an aggravating factor in some other pathologies. Apart from immune components like chemokines, cytokines, receptors, serine proteases are now recognized as key elements through their role in the modulation of immune response, vascular systems, and tissue 


\section{Neutrophil elastase}<smiles>[R]c1c([R])n([R])c([R])c(C(=O)NC([R])([R])C2CCCC([R7])C2)c1=O</smiles>

Substituted 4-pyridones US9346794 B1

[142]<smiles>[R1]C1=C(C)N(c2cccc(C(F)(F)F)c2)c2nn([R])c(=O)n2C1c1ccc(C#N)cc1[R]</smiles>

Tetrahydrotriazolopyrimidine derivatives WO 2013037809 A1

[143]

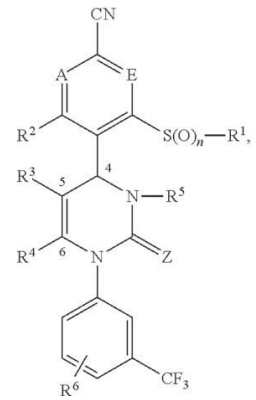

4-(4-cyano-2 thioaryl)dihydropyrimidinones

$A$ and $E$ both represent $C-R^{7}$ or one of the two ring members $A$ and $E$ represents $\mathrm{N}$ and the other represents $\mathrm{C}-\mathrm{R}^{7}$, in which $\mathrm{R}^{7}$ represents in each case hydrogen, fluorine or chlorine, $\mathrm{Z}$ represents $\mathrm{O}$ or $\mathrm{S}, \mathrm{n}$ represents the number 0 , 1 or 2 US 20140045802 A1

Figure 4. Chemical scaffolds and patent references of selected neutrophil elastase inhibitors. (a) Substituted 4-pyridones, Ref [149]. (b) BAY 85-8501, Bayer ${ }^{\circledR}$, Ref [86,150-152]. (c) Tetrahydrotriazolopyrimidine derivatives, Ref [153]. (d) Substituted bicyclic dihydropyrimidinones, Ref [154]. (e) 4-(4-cyano-2 thioaryl)dihydropyrimidinones, (a) and (e) both represent $C-R^{7}$ or one of the two ring members (a) and (e) represents $N$ and the other represents $C-R^{7}$, in which $R^{7}$ represents in each case hydrogen, fluorine or chlorine, $\mathrm{Z}$ represents $\mathrm{O}$ or $\mathrm{S}, \mathrm{n}$ represents the number 0,1 or 2 , Ref [151].

remodeling. However, the design of specific inhibitors has been very challenging for a long time. Nowadays, a large repertoire of serine protease inhibitors is available ranging from peptides/peptidomimetics, natural products, and small-organic molecules. However optimizations are still needed to reach appropriate properties compatible with clinical development. In this review, through a survey of the recent patent literature, we notice that the inhibitors of serine proteases involved in skin diseases were the most actively patented. This statement is certainly due to recent efforts made by both clinicians and scientist to dissect out molecular events behind these diseases that some of them like psoriasis are associated to a wide set of prevalent chronic diseases for example diabetes and cardiovascular diseases. Further investigations are still needed to confirm if these compounds can enter the phase of the clinical evaluation since pharmaceutical firms are currently changing their strategy by huge efforts to rather develop biologicals than small molecules.

\section{Expert opinion}

Serine protease inhibitors to treat inflammatory diseases are being actively investigated by various industrial and academic institutions. Until recently, the unique inhibitors that reached the clinic were concerned coagulation dysfunctions, 


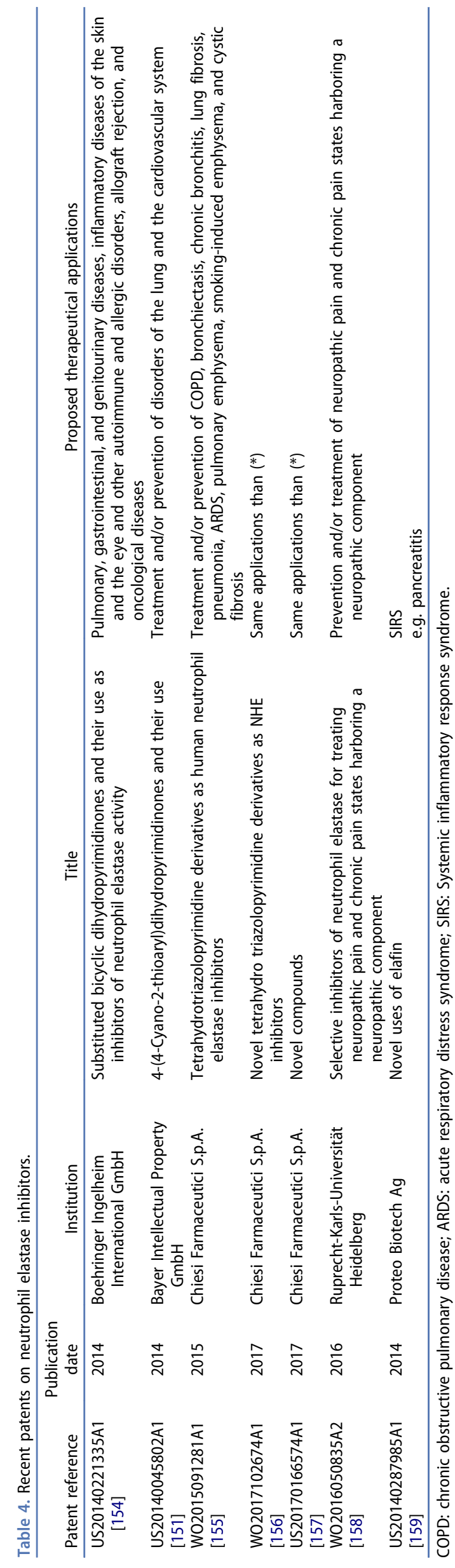

acute inflammation (pancreatitis), and hypertension. Beside anticoagulants, FDA approval of telaprevir and boceprevir for the treatment of hepatitis $C$ virus, the development of new serine protease inhibitors, is likely to be one of the hottest areas in the pharmaceutical industry. The present review focused on inflammatory diseases and the potential of developing serine protease inhibitors most of the targets in this period of 2011-2016 are of tryptic specificity. The patent applications reported here show a large use of rational design based on both known reactivity of the selected chemical scaffolds and the structural properties of targeted serine proteases, as well as combinatory chemistry. In vitro and in silico screenings are underrepresented. In terms of chemical scaffolds, nitrogen-containing heterocycles were the most investigated compounds, they display nanomolar inhibitory potencies. Interestingly, the classical benzylamine moiety received a gain of interest by the development of several original chemical series. Within the analyzed period, plasma kallikrein was the most actively investigated, up to 20 series of inhibitors have been developed. Most the peptide-based or peptidomimetics designed were inspired from biologically occurring inhibitors. Over the analyzed period, the selected patents underlined a competitive atmosphere between pharma firms underlining a gain of interest especially for plasma kallikrein. The patents also bring evidence that chemical scaffolds (heterocycles) are closely related and that the pharmacomodulation was incorporated for fitting in the $S_{1}$ or $S_{1^{\prime}}$ pocket. Most of the investigated inhibitors showed good pharmacokinetic profile and demonstrated quite good efficiency on pathology models that were used to bring proof of concepts. Except for benzylamine that is an extensively investigated chemical scaffold for serine proteases inhibitors, all other compounds constituted original series. All the reported lead compounds showed quite good efficiencies with $\mathrm{K}_{\mathrm{i}}$ or $\mathrm{IC}_{50}$ in the nanomolar range. Nearly all of them were incorporated in at least a preclinical evaluation process. As previously said, these last 5-6 years showed quite dynamic investment in epidermis kallikrein-related peptidases in the field of skin diseases especially through the development of coumarin suicide inhibitors [138] or SFTI-inspired cyclic peptides, both series of compounds displayed good preclinical features namely by lowering stratum corneum damaging, these compounds may be considered to be used as topical preparation. Recently, heteroarylcarboxamide derivatives were reported as very potent low nanomolar inhibitors of plasma kallikrein for treatment of retinal vascular permeability associated with diabetic retinopathy and diabetic macular edema. Interestingly, HNE inhibitors demonstrated innovative strategies to cure lung inflammation. A very recent study has identified BAY 85-8501 as a modern inhibitor that binds to HNE via an induced fit. This inhibitor is characterized by a frozen bioactive conformation that allows the enhancement of inhibitory potency and in vivo pharmacokinetics parameters [150]. This compound entered phase II clinical trials for patients with non-cystic fibrosis bronchiectasis. Moreover, AZD9668 another HNE potent reversible inhibitor, with $\mathrm{IC}_{50} 12-50 \mathrm{nM}$, already succeeded in preclinical studies and is now under phase II clinical trial for bronchiolitis 
obliterans syndrome that is a complication for patient after hematopoietic stem-cell transplant. Despite the increasing interest, no significant patents dealing serine proteases inhibitors to treat $\mathrm{Gl}$ inflammatory diseases have been identified within the investigated period. However, various preclinical studies using reference inhibitors brought the proof of concept that pharmacological inhibition of key serine proteases in $\mathrm{Gl}$ disorders decreases inflammatory components.

\section{Funding}

The authors are grateful to Université Pierre et Marie Curie (UPMC), Institut National pour la Recherche Médicale (INSERM), Centre National de la Recherche Scientifique (CNRS) for research founding and to the French Ministry of Research and Education for F. S. PhD fellowship. We also thank Adrien Bussard from the SATTLetch for his kind help with patent search tools.

\section{Declaration of interest}

The authors have no other relevant affiliations or financial involvement with any organization or entity with a financial interest in or financial conflict with the subject matter or materials discussed in the manuscript apart from those disclosed.

\section{References}

Papers of special note have been highlighted as either of interest $(\cdot)$ or of considerable interest (.•) to readers.

1. Page MJ, Di Cera E. Serine peptidases: classification, structure and function. Cell Mol Life Sci. 2008;65(7-8):1220-1236.

- Very useful review on serine proteases.

2. Di Cera E. Serine proteases. IUBMB Life. 2009 May;61(5):510-515.

3. Turk B. Targeting proteases: successes, failures and future prospects. Nat Rev Drug Discov. 2006;5(9):785-799.

4. Prassas I, Eissa A, Poda G, et al. Unleashing the therapeutic potential of human kallikrein-related serine proteases. Nat Rev Drug Discov. 2015;14(3):183-202.

5. Drag M, Salvesen GS. Emerging principles in protease-based drug discovery. Nat Rev Drug Discov. 2010;9(9):690-701.

6. Ursu O, Holmes J, Knockel J, et al. DrugCentral: online drug compendium. Nucleic Acids Res. 2017;45(D1):D932-D939.

7. Zhong J, Groutas WC. Recent developments in the design of mechanism-based and alternate substrate inhibitors of serine proteases. Curr Top Med Chem. 2004;4(12):1203-1216.

8. Liang G, Bowen JP. Development of trypsin-like serine protease inhibitors as therapeutic agents: opportunities, challenges, and their unique structure-based rationales. Curr Top Med Chem. 2016;16(13):1506-1529.

- Very documented review on the various class of inhibitors on their mechanism of action.

9. Krowarsch D, Cierpicki T, Jelen F, et al. Canonical protein inhibitors of serine proteases. Cell Mol Life Sci. 2003;60(11):2427-2444.

10. Waldner BJ, Fuchs JE, Schauperl M, et al. Protease inhibitors in view of peptide substrate databases. J Chem Inf Model. 2016;56(6):1228-1235.

11. Turk $B$, Turk $D$, Turk V. Protease signalling: the cutting edge. Embo J. 2012;31(7):1630-1643.

-. Outstanding review on the implication of serine proteases in the cellular and physiological processes.

12. Heutinck KM, Ten Berge IJ, Hack CE, et al. Serine proteases of the human immune system in health and disease. Mol Immunol. 2010;47(11-12):1943-1955.

.- Important review in the field of immunity and the role of serine proteases.
13. Sharony R, Yu PJ, Park J, et al. Protein targets of inflammatory serine proteases and cardiovascular disease. J Inflamm (Lond). 2010;7:45.

14. Schranz J, Adelman B, Chyung Y. Plasma kallikrein inhibitors and uses thereof for treating hereditary angioedema attack patent WO2017100679A1. 2017.

15. Meyer-Hoffert U. Reddish, scaly, and itchy: how proteases and their inhibitors contribute to inflammatory skin diseases. Arch Immunol Ther Exp (Warsz). 2009;57(5):345-354.

16. Two AM, Hata TR, Nakatsuji T, et al. Reduction in serine protease activity correlates with improved rosacea severity in a small, randomized pilot study of a topical serine protease inhibitor. J Invest Dermatol. 2014;134(4):1143-1145.

17. De Veer SJ, Furio L, Harris JM, et al. Proteases: common culprits in human skin disorders. Trends Mol Med. 2014;20(3):166-178.

18. De Veer SJ, Furio L, Harris JM, et al. Proteases and proteomics: cutting to the core of human skin pathologies. Proteomics Clin Appl. 2014;8(5-6):389-402.

19. Rawlings ND, Barrett AJ, Bateman A. Using the MEROPS database for proteolytic enzymes and their inhibitors and substrates. Curr Protoc Bioinformatics. 2014;12(48):1-33.

20. Schechter I, Berger A. On the size of the active site in proteases. I. Papain. Biochem Biophys Res Commun. 1967;27(2):157-162.

- Classical references in the field of proteases' classification and mechanism of action.

21. Hedstrom L. Serine protease mechanism and specificity. Chem Rev. 2002;102(12):4501-4524.

.. Unavoidable reference on serine proteases' enzymology.

22. Hedstrom L. An overview of serine proteases. Curr Protoc Protein Sci. 2002;Chapter 21:Unit 2110.

23. Harris JL, Backes BJ, Leonetti $F$, et al. Rapid and general profiling of protease specificity by using combinatorial fluorogenic substrate libraries. Proc Natl Acad Sci U S A. 2000;97(14):7754-7759.

24. Sanman LE, Bogyo M. Activity-based profiling of proteases. Annu Rev Biochem. 2014;83:249-273.

25. Kasperkiewicz $\mathrm{P}$, Poreba $\mathrm{M}, \mathrm{Groborz} K$, et al. Emerging challenges in the design of selective substrates, inhibitors and activity-based probes for indistinguishable proteases. Febs J. 2017;284(10):1518-1539.

26. Edgington-Mitchell LE, Barlow N, Aurelio L, et al. Fluorescent diphenylphosphonate-based probes for detection of serine protease activity during inflammation. Bioorg Med Chem Lett. 2017;27 (2):254-260.

27. Kasperkiewicz P, Altman Y, D'Angelo $M$, et al. Toolbox of fluorescent probes for parallel imaging reveals uneven location of serine proteases in neutrophils. J Am Chem Soc. 2017;139(29):1011510125.

.. Very elegant report on the in situ monitoring of proteases' activity in neutrophils.

28. Medzhitov R. Inflammation 2010: new adventures of an old flame. Cell. 2010;140(6):771-776.

- Very important review on the molecular mechanisms behind inflammation.

29. Scrivo R, Vasile M, Bartosiewicz I, et al. Inflammation as "common soil" of the multifactorial diseases. Autoimmun Rev. 2011 May;10 (7):369-374

30. Mancek-Keber M. Inflammation-mediating proteases: structure, function in (patho) physiology and inhibition. Protein Pept Lett. 2014;21(12):1209-1229.

- Useful review on the role of proteases in inflammation.

31. Ramachandran R, Altier C, Oikonomopoulou K, et al. Proteinases, their extracellular targets, and inflammatory signaling. Pharmacol Rev. 2016;68(4):1110-1142.

32. Hollenberg MD, Mihara $K$, Polley $D$, et al. Biased signalling and proteinase-activated receptors (PARs): targeting inflammatory disease. Br J Pharmacol. 2014;171(5):1180-1194.

33. Pham CT. Neutrophil serine proteases fine-tune the inflammatory response. Int J Biochem Cell Biol. 2008;40(6-7):1317-1333.

34. Abbenante G, Fairlie DP. Protease inhibitors in the clinic. Med Chem. 2005;1(1):71-104. 
35. Pasparakis M, Haase I, Nestle FO. Mechanisms regulating skin immunity and inflammation. Nat Rev Immunol. 2014;14(5):289-301.

-. Outstanding review of inflammatory processes in the skin.

36. Malik K, Heitmiller KD, Czarnowicki T. An update on the pathophysiology of atopic dermatitis. Dermatol Clin. 2017 Jul;35(3):317-326.

37. Vavrova K. Emerging small-molecule compounds for treatment of atopic dermatitis: a review. Expert Opin Ther Pat. 2016;26(1):21-34.

38. Sidbury R, Khorsand K. Evolving concepts in atopic dermatitis. Curr Allergy Asthma Rep. 2017;17(7):42.

39. Bieber T. Atopic dermatitis. Ann Dermatol. 2010;22(2):125-137.

40. Bieber T. How to define atopic dermatitis? Dermatol Clin. 2017;35 (3):275-281.

41. Parisi R, Symmons DP, Griffiths CE, et al. Global epidemiology of psoriasis: a systematic review of incidence and prevalence. J Invest Dermatol. 2013 Feb;133(2):377-385. PubMed PMID: 23014338. DOI:10.1038/jid.2012.339

42. Springate DA, Parisi R, Kontopantelis $E$, et al. Incidence, prevalence and mortality of patients with psoriasis: a U.K. population-based cohort study. Br J Dermatol. 2017;176(3):650-658.

43. Guttman-Yassky E, Krueger JG, Lebwohl MG. Systemic immune mechanisms in atopic dermatitis and psoriasis with implications for treatment. Exp Dermatol. 2017 Mar 07.

44. Zhu Y, Underwood J, Macmillan D, et al. Persistent kallikrein 5 activation induces atopic dermatitis-like skin architecture independent of PAR2 activity. J Allergy Clin Immunol. 2017;140:1310-1322.

45. Morizane S, Yamasaki K, Kajita A, et al. TH2 cytokines increase kallikrein 7 expression and function in patients with atopic dermatitis. J Allergy Clin Immunol. 2012;130(1):259-261 e1.

46. Two AM, Wu W, Gallo RL, et al. Rosacea: part II. Topical and systemic therapies in the treatment of rosacea. J Am Acad Dermatol. 2015;72(5):761-770; quiz 771-772.

47. Two AM, Wu W, Gallo RL, et al. Rosacea: part I. Introduction, categorization, histology, pathogenesis, and risk factors. J Am Acad Dermatol. 2015;72(5):749-758; quiz 759-760.

48. Yamasaki K, Di Nardo A, Bardan A, et al. Increased serine protease activity and cathelicidin promotes skin inflammation in rosacea. Nat Med. 2007;13(8):975-980.

49. Takahashi T, Gallo RL. The critical and multifunctional roles of antimicrobial peptides in dermatology. Dermatol Clin. 2017;35 (1):39-50.

50. Yamasaki K, Gallo RL. The molecular pathology of rosacea. J Dermatol Sci. 2009;55(2):77-81.

51. Hovnanian A. Netherton syndrome: skin inflammation and allergy by loss of protease inhibition. Cell Tissue Res. 2013;351(2):289-300.

52. Furio L, Hovnanian A. Netherton syndrome: defective kallikrein inhibition in the skin leads to skin inflammation and allergy. Biol Chem. 2014;395(9):945-958.

53. Leclerc-Mercier S, Bodemer C, Furio L, et al. Skin biopsy in netherton syndrome: a histological review of a large series and new findings. Am J Dermatopathol. 2016;38(2):83-91.

54. Bonnart C, Deraison C, Lacroix M, et al. Elastase 2 is expressed in human and mouse epidermis and impairs skin barrier function in Netherton syndrome through filaggrin and lipid misprocessing. J Clin Invest. 2010;120(3):871-882.

55. Briot A, Deraison C, Lacroix $M$, et al. Kallikrein 5 induces atopic dermatitis-like lesions through PAR2-mediated thymic stromal lymphopoietin expression in Netherton syndrome. J Exp Med. 2009;206(5):1135-1147.

56. Briot A, Lacroix $M$, Robin A, et al. Par2 inactivation inhibits early production of TSLP, but not cutaneous inflammation, in Netherton syndrome adult mouse model. J Invest Dermatol. 2010;130(12):2736-2742.

57. Descargues $P$, Deraison C, Bonnart C, et al. Spink5-deficient mice mimic Netherton syndrome through degradation of desmoglein 1 by epidermal protease hyperactivity. Nat Genet. 2005;37(1):56-65.

58. Fortugno P, Bresciani A, Paolini C, et al. Proteolytic activation cascade of the Netherton syndrome-defective protein, LEKTI, in the epidermis: implications for skin homeostasis. J Invest Dermatol. 2011;131(11):2223-2232.
59. Reindl J, Pesek J, Kruger T, et al. Proteomic biomarkers for psoriasis and psoriasis arthritis. J Proteomics. 2016;140:55-61.

60. Elias MS, Long HA, Newman CF, et al. Proteomic analysis of filaggrin deficiency identifies molecular signatures characteristic of atopic eczema. J Allergy Clin Immunol. 2017;140:1299-1309.

61. Kasparek P, lleninova Z, Zbodakova O, et al. KLK5 and KLK7 ablation fully rescues lethality of netherton syndrome-like phenotype. PLoS Genet. 2017;13(1):e1006566.

62. West JB. Respiratory physiology: the essentials. Lippincott Williams \& Wilkins; 2012

63. Moldoveanu $B$, Otmishi $P$, Jani $P$, et al. Inflammatory mechanisms in the lung. J Inflamm Res. 2009;2:1-11.

64. Eapen MS, Myers S, Walters EH, et al. Airway inflammation in chronic obstructive pulmonary disease (COPD): a true paradox. Expert Rev Respir Med. 2017;11:827-839.

65. Kettritz R. Neutral serine proteases of neutrophils. Immunol Rev. 2016;273(1):232-248.

66. Vergnolle N. Protease inhibition as new therapeutic strategy for Gl diseases. Gut. 2016;65(7):1215-1224.

- Excellent review on the targeting of proteases in GI disorders.

67. Kamm MA. Rapid changes in epidemiology of inflammatory bowel disease. Lancet. 2017 Oct 13.

68. Biancheri P, Di Sabatino A, Corazza GR, et al. Proteases and the gut barrier. Cell Tissue Res. 2013;351(2):269-280.

- Excellent references on the roles of proteases in gut physiology.

69. Van Spaendonk H, Ceuleers H, Witters L, et al. Regulation of intestinal permeability: the role of proteases. World J Gastroenterol. 2017;23(12):2106-2123.

70. Steck N, Mueller K, Schemann M, et al. Bacterial proteases in IBD and IBS. Gut. 2012;61(11):1610-1618.

71. Ceuleers H, Segaert E, Heirbaut J, et al. Su1937 two serine protease inhibitors, nafamostat mesylate and the newly developed SPIx, decrease post-inflammatory visceral hypersensitivity in rats. Gastroenterology. 2016;150(4):S593-S594.

72. Van Spaendonk H, Nullens S, Ceuleers H, et al. Tu1883 the effect of a protease inhibitor in a chronic colitis transfer model. Gastroenterology. 2016;150(4):S967.

73. Clements J, Hooper J, Dong Y, et al. The expanded human kallikrein (KLK) gene family: genomic organisation, tissue-specific expression and potential functions. Biol Chem. 2001;382(1):5-14.

74. Lundwall A, Band V, Blaber $M$, et al. A comprehensive nomenclature for serine proteases with homology to tissue kallikreins. Biol Chem. 2006;387(6):637-641.

75. Paliouras M, Diamandis EP. The kallikrein world: an update on the human tissue kallikreins. Biol Chem. 2006;387(6):643-652.

76. Emami N, Diamandis EP. New insights into the functional mechanisms and clinical applications of the kallikrein-related peptidase family. Mol Oncol. 2007 Dec;1(3):269-287.

77. Emami N, Diamandis EP. Human tissue kallikreins: a road under construction. Clin Chim Acta. 2007;381(1):78-84.

78. Kalinska M, Meyer-Hoffert U, Kantyka T, et al. Kallikreins - the melting pot of activity and function. Biochimie. 2016;122:270-282.

79. Lizama AJ, Andrade $Y$, Colivoro $P$, et al. Expression and bioregulation of the kallikrein-related peptidases family in the human neutrophil. Innate Immun. 2015;21(6):575-586.

80. Bjorkqvist J, Jamsa A, Renne T. Plasma kallikrein: the bradykininproducing enzyme. Thromb Haemost. 2013;110(3):399-407.

81. Weidmann $H$, Heikaus L, Long AT, et al. The plasma contact system, a protease cascade at the nexus of inflammation, coagulation and immunity. Biochim Biophys Acta. 2017;1864:2118-2127.

82. Okada Y, Tsuda Y, Tada M, et al. Development of plasma kallikrein selective inhibitors. Biopolymers. 1999;51(1):41-50.

83. Sotiropoulou G, Pampalakis G. Targeting the kallikrein-related peptidases for drug development. Trends Pharmacol Sci. 2012;33 (12):623-634

84. Masurier N, Arama DP, El Amri C, et al. Inhibitors of kallikreinrelated peptidases: an overview. Med Res Rev. 2017 Jun 13. 
85. Goettig P, Magdolen V, Brandstetter H. Natural and synthetic inhibitors of kallikrein-related peptidases (KLKs). Biochimie. 2010 Nov;92(11):1546-1567.

86. Von Nussbaum F, Li VM. Neutrophil elastase inhibitors for the treatment of (cardio)pulmonary diseases: into clinical testing with pre-adaptive pharmacophores. Bioorg Med Chem Lett. 2015;25 (20):4370-4381.

87. Henriksen PA. The potential of neutrophil elastase inhibitors as anti-inflammatory therapies. Curr Opin Hematol. 2014;21(1):23-28.

88. Benarafa C, Simon HU. Role of granule proteases in the life and death of neutrophils. Biochem Biophys Res Commun. 2017;482 (3):473-481.

89. Pham CT. Neutrophil serine proteases: specific regulators of inflammation. Nat Rev Immunol. 2006;6(7):541-550.

-. Outstanding review on the role of neutrophil serine proteases in inflammation.

90. Meyer-Hoffert U, Wiedow O. Neutrophil serine proteases: mediators of innate immune responses. Curr Opin Hematol. 2011;18(1):19-24.

91. Wiedow O, Meyer-Hoffert U. Neutrophil serine proteases: potential key regulators of cell signalling during inflammation. J Intern Med. 2005;257(4):319-328.

92. Ramachandran $\mathrm{R}$, Mihara $\mathrm{K}$, Chung $\mathrm{H}$, et al. Neutrophil elastase acts as a biased agonist for proteinase-activated receptor-2 (PAR2). J Biol Chem. 2011;286(28):24638-24648.

93. Belaaouaj A, McCarthy R, Baumann M, et al. Mice lacking neutrophil elastase reveal impaired host defense against gram negative bacterial sepsis. Nat Med. 1998;4(5):615-618.

94. Tsai YF, Hwang TL. Neutrophil elastase inhibitors: a patent review and potential applications for inflammatory lung diseases (20102014). Expert Opin Ther Pat. 2015;25(10):1145-1158.

95. Twigg MS, Brockbank S, Lowry $P$, et al. The role of serine proteases and antiproteases in the cystic fibrosis lung. Mediators Inflamm. 2015;2015:293053.

96. Hagiwara S, Iwasaka H, Hidaka S, et al. Neutrophil elastase inhibitor (sivelestat) reduces the levels of inflammatory mediators by inhibiting NF-kB. Inflamm Res. 2009;58(4):198-203.

97. Hagiwara S, Iwasaka $H$, Togo K, et al. A neutrophil elastase inhibitor, sivelestat, reduces lung injury following endotoxin-induced shock in rats by inhibiting HMGB1. Inflammation. 2008;31(4):227-234.

98. Yoshimura Y, Hiramatsu Y, Sato Y, et al. ONO-6818, a novel, potent neutrophil elastase inhibitor, reduces inflammatory mediators during simulated extracorporeal circulation. Ann Thorac Surg. 2003;76 (4):1234-1239.

99. Lee JM, Yeo CD, Lee HY, et al. Inhibition of neutrophil elastase contributes to attenuation of lipopolysaccharide-induced acute lung injury during neutropenia recovery in mice. J Anesth. 2017;31(3):397-404.

100. Stevens T, Ekholm K, Granse M, et al. AZD9668: pharmacological characterization of a novel oral inhibitor of neutrophil elastase. J Pharmacol Exp Ther. 2011;339(1):313-320.

101. Kuna $P$, Jenkins $M, O^{\prime} B$ rien $C D$, et al. AZD9668, a neutrophil elastase inhibitor, plus ongoing budesonide/formoterol in patients with COPD. Respir Med. 2012;106(4):531-539.

102. Muley MM, Reid AR, Botz B, et al. Neutrophil elastase induces inflammation and pain in mouse knee joints via activation of proteinase-activated receptor-2. Br J Pharmacol. 2016;173(4):766-777.

- Preclinal study on neutrophil elastase inhibition in joint diseases.

103. Muley MM, Krustev E, Reid AR, et al. Prophylactic inhibition of neutrophil elastase prevents the development of chronic neuropathic pain in osteoarthritic mice. J Neuroinflammation. 2017;14 (1):168.

- Preclinical studies on neutrophil elastase inhibition in joint diseases.

104. Bao Y, Hou W, Hua B. Protease-activated receptor 2 signalling pathways: a role in pain processing. Expert Opin Ther Targets. 2014;18(1):15-27.

105. Castellino FJ, Ploplis VA. Structure and function of the plasminogen/plasmin system. Thromb Haemost. 2005;93(4):647-654.
106. Law RHP, Caradoc-Davies T, Cowieson N, et al. The X-ray crystal structure of full-length human plasminogen. Cell Rep. 2012;1 (3):185-190.

107. Law RHP, Abu-Ssaydeh D, Whisstock JC. New insights into the structure and function of the plasminogen/plasmin system. Curr Opin Struct Biol. 2013;23(6):836-841.

108. Wang $X$, Lin $X$, Loy JA, et al. Crystal structure of the catalytic domain of human plasmin complexed with streptokinase. Science. 1998;281(5383):1662-1665.

109. Wang X, Terzyan S, Tang J, et al. Human plasminogen catalytic domain undergoes an unusual conformational change upon activation. J Mol Biol. 2000;295(4):903-914.

110. Hervio LS, Coombs GS, Bergstrom RC, et al. Negative selectivity and the evolution of protease cascades: the specificity of plasmin for peptide and protein substrates. Chem Biol. 2000;7(6):443-453.

111. Foley JH. Plasmin(ogen) at the nexus of fibrinolysis, inflammation, and complement. Semin Thromb Hemost. 2017;43(2):135-142.

112. Draxler DF, Sashindranath M, Medcalf RL. Plasmin: a modulator of immune function. Semin Thromb Hemost. 2017;43(2):143-153.

113. Shimazu $H$, Munakata S, Tashiro $Y$, et al. Pharmacological targeting of plasmin prevents lethality in a murine model of macrophage activation syndrome. Blood. 2017;130:59-72.

114. Hamilton JA. Plasminogen activator/plasmin system in arthritis and inflammation: friend or foe? Arthritis Rheum. 2008;58(3):645-648.

115. Al-Horani RA, Desai UR. Recent advances on plasmin inhibitors for the treatment of fibrinolysis-related disorders. Med Res Rev. 2014;34(6):1168-1216.

116. Swedberg JE, Harris JM. Plasmin substrate binding site cooperativity guides the design of potent peptide aldehyde inhibitors. Biochemistry. 2011;50(39):8454-8462.

117. Swedberg JE, Harris JM. Natural and engineered plasmin inhibitors: applications and design strategies. Chembiochem. 2012;13(3):336348.

118. Edwards HJ, Evans DM, Davie RM, et al. Bicyclic inhibitors patent WO 2015022547 A1. 2015.

119. Smith AL, Novak AR, Evans DM, et al. N-((heteroarylmethyl)-heteroaryl-carboxamide derivatives as plasma kallikrein inhibitors patent WO 2016083816 A1. 2016.

120. Evans DM, Davie RL, Edwards HJ, et al. Benzylamine derivatives as inhibitors of plasma kallikrein patent US 9051249 B2. 2015.

121. Northen JS, Mykytiuk J. Polymorphs of N-[(R)-1-[(S)-1-(4-aminomethylbenzylcarbamoyl)-2-phenyl-ethylcarbamoyl]-2-(4-ethoxy-phenyl)ethyl]-benzamide hydrochloride patent US 9512065 B2. 2016.

122. Davie RL, Edwards HJ, Evans DM, et al. inventorHeterocyclic derivates patent US 9533987 B2. 2017.

123. Allan CE, Batt AR, Davie RL, et al. Benzylamine derivatives patent US 9670157 B2. 2017.

124. Kotian PL, Babu YS, Kumar VS, et al. inventorHuman plasma kallikrein inhibitors patent WO 2017059178 A1. 2017.

125. Wang $Z$, Ye $P$, Alonso $R$, et al. Peptide and peptidomimetic inhibitors patent US20170189470A1. 2017.

126. Chrusciel RA, Gadwood RC, Hayward NJ, et al. inventorTherapeutic compounds and compositions patent US 20170037003 A1. 2017.

127. Teufel $D$, Stace $C$, Walker E. Benzylamine derivatives as inhibitors of plasma kallikrein patent US 20160222063 A1. 2016.

128. Teufel D, Stace C, Walker E. Novel polypeptides patent US 20160222063 A1. 2016.

129. Flohr S, Markert C, Namoto K, et al. 5-membered heteroarylcarboxamide derivatives as plasma kallikrein inhibitors patent WO 2013111108 A1. 2013.

130. Markland WR. Kallikrein-binding "kunitz domain" proteins and analogues thereof patent US 20120328517 A1. 2012.

131. Scott CJ, Taggart CC. Biologic protease inhibitors as novel therapeutic agents. Biochimie. 2010;92(11):1681-1688.

132. Krantz A. A classification of enzyme inhibitors. Bioorg Med Chem Lett. 1992;2(11):1327-1334.

133. Kolte D, Bryant J, Holsworth D, et al. Biochemical characterization of a novel high-affinity and specific plasma kallikrein inhibitor. $\mathrm{Br} \mathrm{J}$ Pharmacol. 2011;162(7):1639-1649. 
134. Kolte D, Bryant JW, Gibson GW, et al. PF-04886847 (an inhibitor of plasma kallikrein) attenuates inflammatory mediators and activation of blood coagulation in rat model of lipopolysaccharide (LPS)induced sepsis. Cardiovasc Hematol Agents Med Chem. 2012;10 (2):154-166.

135. Kolte D, Shariat-Madar Z. Plasma kallikrein inhibitors in cardiovascular disease: an innovative therapeutic approach. Cardiol Rev. 2016;24(3):99-109.

136. Frattini S, Bakker R, Giovannini R, et al. Heteroarylcarboxamide derivatives as plasma kallikrein inhibitors patent WO 2017072020 A1. 2017.

137. Li Z, Partridge J, Silva-Garcia A, et al. Structure-guided design of novel, potent, and selective macrocyclic plasma kallikrein inhibitors. ACS Med Chem Lett. 2017;8(2):185-190.

138. Reboud-Ravaux M, El Amri C, Tan X, et al. Use of coumarin derivatives for the preparation of drugs for treating skin diseases patent WO 2013010963 A1. 2013.

139. Short KM, Pham SM, Williams DC, et al. Multisubstituted aromatic compounds as serine protease inhibitors patent US 20170065570 A1. 2017.

140. Harris JM, De Veer SJ, Swedberg JE. Serine protease inhibitors patent WO 2012083385 A1. 2012.

141. Wang FY, Tan X, Wang D, et al. Kallikrein 7 small-molecule inhibitor and preparation method and purpose thereof patent $\mathrm{CN}$ 106518880 A. 2017.

142. Short KM, Ben Kita D, De Los Angeles Estiarte-Martinez M, et al. Pyrazolyl-substituted pyridone compounds as serine protease inhibitors patent WO 2016044662 A1. 2016.

143. Wang FY, Tan $X$, Wang $D$, et al. Kallikrein KLK7 inhibiting compound and preparation method and application thereof patent $\mathrm{CN}$ 105330665 A. 2016.

144. Joossens J, Augustyns K, Lambeir AM, et al. Novel klk4 inhibitors patent WO 2015144933 A1. 2015.

145. Wagberg F, Leonardsson G. Benzoxazinone derivatives for treatment of skin diseases patent WO 2015112081 A1. 2015.

146. Tan X, Soualmia F, Furio L, et al. Toward the first class of suicide inhibitors of kallikreins involved in skin diseases. J Med Chem. 2015;58(2):598-612.

147. Koistinen $\mathrm{H}$, Wohlfahrt $\mathrm{G}$, Mattsson $J M$, et al. Novel small molecule inhibitors for prostate-specific antigen. Prostate. 2008;68(11):11431151.

148. Chen W, Kinsler VA, Macmillan D, et al. Tissue kallikrein inhibitors based on the sunflower trypsin inhibitor scaffold - a potential therapeutic intervention for skin diseases. PLoS One. 2016;11(11): e0166268.

149. Oost T, Fiegen D, Gnamm C. Substituted 4-pyridones and their use as inhibitors of neutrophil elastase activity patent US9346794 B1. 2016.

150. Von Nussbaum F, Li VM, Allerheiligen $\mathrm{S}$, et al. Freezing the bioactive conformation to boost potency: the identification of BAY 85-8501, a selective and potent inhibitor of human neutrophil elastase for pulmonary diseases. Chem Med Chem. 2015;10 (7):1163-1173.

151. Von Nussbaum F, Karthaus D, Anlauf $S$, et al. 4-(4-cyano-2-thioaryl) dihydropyrimidinones and their use patent US 20140045802 A1. 2014.

152. Von Nussbaum F, Li VM, Meibom D, et al. Potent and selective human neutrophil elastase inhibitors with novel equatorial ring topology: in vivo efficacy of the polar pyrimidopyridazine BAY8040 in a pulmonary arterial hypertension rat model. ChemMedChem. 2016;11(2):199-206.

.. Very elegant strategy of inhibitor design of neutrophil elastase.

153. Blench JT, Edwards C, Heald RA, et al. Tetrahydrotriazolopyrimidine derivatives as human neutrophil elastase inhibitors patent WO 2013037809 A1. 2013.

154. Gnamm C, Oost T, Peters S. Substituted bicyclic dihydropyrimidinones and their use as inhibitors of neutrophil elastase activity patent US 20140221335 A1. 2014.

155. Alcaraz L, Sutton JM, Calpadi C, et al. Tetrahydrotriazolopyrimidine derivatives as human neutrophil elastase inhibitors patent WO2015091281 A1. 2015.

156. Armani E, Capaldi C. Novel tetrahydrotriazolopyrimidine derivatives as nhe inhibitors. WO 2017102674 A1. 2017.

157. Armani E, Capaldi C. Novel compounds patent US 20170166574 A1. 2017.

158. Vicuna L, Simonetti M, Bali KK, et al. Selective inhibitors of neutrophil elastase for treating neuropathic pain and chronic pain states harbouring a neuropathic component patent WO 2016050835 A2. 2016.

159. Wiedow O, Bargmann B, Kahlke B, et al. inventorNovel uses of elafin patent US20140287985 A1. 2014

160. Nickel NP, Spiekerkoetter E, Gu M, et al. Elafin reverses pulmonary hypertension via caveolin-1-dependent bone morphogenetic protein signaling. Am J Respir Crit Care Med. 2015 Jun 01;191 (11):1273-1286. 